NBER WORKING PAPER SERIES

\title{
BUSINESS PARTNERS, FINANCING, AND THE COMMERCIALIZATION OF INVENTIONS
}

\author{
Thomas Åstebro \\ Carlos J. Serrano \\ Working Paper 17181 \\ http://www.nber.org/papers/w17181 \\ NATIONAL BUREAU OF ECONOMIC RESEARCH \\ 1050 Massachusetts Avenue \\ Cambridge, MA 02138 \\ June 2011
}

We have benefited from the comments of Victor Aguirregabiria, Serguei Braguinsky, Alberto Galasso, Bart Hamilton, Octavian Harare, Ig Horstmann, Alexander Kritikos, Illoong Kwon, Robert Petrunia, Peter Thompson, Aloysius Siow, Sheryl Winston Smith, Scott Stern, and seminar participants at the DRUID conference 2008, REER conference in Georgia Tech 2008, Society of Economic Dynamics 2008, University of Chile, International Industrial Organization conference 2009, EARIE 2009, EEA 2009 meetings, Spanish Economic Association Meetings 2009, Canadian Economic Association Meetings 2010, Amsterdam Center for Entrepreneurship (ACE) workshop 2010, the University of Nottingham, LBS Sumantra Ghoshal Strategy Conference, and the Fourth Searle Conference on Entrepreneurhip and Innovation. Åstebro acknowledges financial support from the Social Sciences and Humanities Research Council, Canada and the Natural Sciences and Engineering Research Council, Canada for data collection and HEC Foundation for support writing this article. Serrano acknowledges financial support from the Social Sciences and Humanities Research Council, Canada, and the Connaught Research Funds from the University of Toronto, Canada. The views expressed herein are those of the authors and do not necessarily reflect the views of the National Bureau of Economic Research.

NBER working papers are circulated for discussion and comment purposes. They have not been peerreviewed or been subject to the review by the NBER Board of Directors that accompanies official NBER publications.

(C) 2011 by Thomas Åstebro and Carlos J. Serrano. All rights reserved. Short sections of text, not to exceed two paragraphs, may be quoted without explicit permission provided that full credit, including (c) notice, is given to the source. 
Business Partners, Financing, and the Commercialization of Inventions

Thomas Åstebro and Carlos J. Serrano

NBER Working Paper No. 17181

June 2011

JEL No. G24,J24,M13,O31

\section{ABSTRACT}

This paper studies the effect of business partners on the commercialization of nvention based ventures, and it assesses the relative importance of partners' human and social capital on commercialization outcomes. Projects run by partnerships were five times more likely to reach commercialization, and they had mean revenues approximately ten times greater than projects run by solo-entrepreneurs. These gross differences may be due both to business partners' value added and to selection. After controlling for selection effects and observed/unobserved heterogeneity, our smallest estimate of partner value added approximately doubles the probability of commercialization and increases expected revenues by $29 \%$ at the sample mean.

Thomas Åstebro

HEC Paris

astebro@hec.fr

Carlos J. Serrano

Department of Economics

University of Toronto

150 St. George Street

Toronto, ON M5S 3G7

CANADA

and NBER

carlos.serrano@utoronto.ca 


\section{Introduction}

Venture capital is now recognized to play an important role in entrepreneurship and financial intermediation. The volume of venture capital commitments — whether in the form of formal venture capital (VC) or informal venture capital - is large. As a natural consequence, whether early stage financiers bring value added to start-ups has become a subject of interest in the entrepreneurial finance literature. However, while scholars have examined the value added by venture fund investors to new ventures, relatively little is still known about the value added of informal venture capital such as angels and business partners, a sector which, by some estimates, is as large or larger than the $\mathrm{VC}$ sector. ${ }^{1}$

In this paper we investigate the impact of informal venture capital on early stage ventures by relying on a survey which documents the human, social, and financial capital contribution of business partners to inventive projects. The raw data from the survey shows a very important role for business partners in commercialization success; the rate of commercialization of projects run by partnerships (0.30) is five times larger than those run by solo entrepreneurs (0.06), and the revenues of projects undertaken by partnerships are almost ten times as large as those run by solo entrepreneurs. The survey answers on the provision of human, social, and financial capital contributions, with some assumptions, allow us to identify how much of these gross effects represent value of obtaining human and social capital while controlling for selection of projects into partnerships. In addition, we provide a simple model to illustrate the value added of informal venture capital, and the sources of selection. The main focus of the paper, however, is to identify empirically the impact of informal venture capital on early stage ventures.

Informal venture capital shares with VCs the role as financial intermediaries, but have somewhat different objectives and modes of operation. Informal venture capital investors typically make only a few investments at a time, tend to invest substantially smaller amounts than VCs, invest their savings on their own or in syndication with other private persons, and they more often than VCs invest in early-stage deals. They are geographically widely distributed and make most investments locally. As opposed to institutional investors they do not, generally, rely on traditional control mechanisms, such as board control, staging or contractual provisions. They rather spend time 'hands-on' in the business or exercise control through other mechanisms such as trust or social influence. Many are active investors who seek to contribute their experience,

\footnotetext{
${ }^{1}$ For example, Reynolds (2005) reports the informal investor sector to $\$ 162$ billion per year over the period 2000 2004 , while formal venture capital were reported to provide $\$ 45$ billion per year to start-ups during 2000-2003. More recently, Sohl (2010), reports U.S. angel investors to have provided $\$ 17.6$ billion in financing for 57,225 projects in 2009 and the (U.S.) National Venture Capital Association report that formal venture capital in the same period provided $\$ 17.7$ billion in financing for 2,795 projects, of which $\$ 1.6$ billion went to 312 startups.
} 
knowledge and contacts to the investee; they often invest in sectors where they have had previous experience, while others are passive investors. Furthermore, informal venture capital takes various forms ranging from the most structured (groups of angels) to the least (individual angels and business partners). ${ }^{2}$

Focusing our empirical analysis on business partners is interesting on its own. Business partnerships are important for the economy; approximately 10\% of all U.S. businesses are partnerships and $18 \%$ of business receipts are from partnerships. ${ }^{3}$ Business partners appear even more important for start-ups. For example, in the panel study of entrepreneurial dynamics, $52 \%$ of start-ups were partnerships (Ruef, Aldrich, and Carter, 2003). But to our knowledge the literature has not clarified specifically why business partners are so important for start-ups. Reflecting conventional wisdom, the business press commonly advises entrepreneurs to partner with people in order to increase the chances to commercialize their ideas. However, the empirical evidence on the value of this advice is scattered. ${ }^{4}$ More importantly, little is known about the mechanisms through which business partnerships are formed.

Documenting that early stage financiers provide a real impact to start-ups has been difficult (Hellmann and Puri, 2000; Hall and Lerner, 2010). There are several complicating factors when trying to quantify the value added of early stage financiers - self-selection and sorting being of primary concern. For instance, if inventions commercialized by partnerships have higher revenues than inventions commercialized by solo entrepreneurs it may reflect that partners provide value added in the form of human or social capital, but it may also reflect that partners join inventors with better inventions (selection on invention quality), or that inventors with better inventions, whom on average are more likely to be credit constrained, enlist partners to obtain financing (selection on demand for financing). The policy implications are vastly different depending on the answer; in the latter case one might ask if there are available policies to relax credit constraints. In the former case one might instead ask for policies to improve the efficiency of the market for finding business partners. Both policies are currently in use in Europe to stimulate business

\footnotetext{
${ }^{2}$ Using a representative survey of 22,000 U.S. households, Bygrave and Reynolds (2006) show that as much as $5 \%$ of household are informal venture investors, $50 \%$ of their investments are received by a relative, $28.5 \%$ by a friend or neighbor, $6.1 \%$ by a colleague at work, and $9.4 \%$ by a stranger. For further descriptive evidence of the informal venture capital sector, see Harrison, Mason, and Robson (2010); Kerr, Lerner, and Schoar (2010) ; Mason (2009); VanOsnabrugge and Robinson (2000); Wong, Bhatia, and Freeman (2009); Wiltbank and Boeker (2007); and Wiltbank (2009).

${ }^{3}$ Statistics of Income, http://www.irs.gov/taxstats/article/0,id=175843,00.html. The approximately 3.1 million U.S. partnerships in 2007 had 18.5 million partners. Excluding limited and limited liability partnerships (popular investment vehicles in the movie and construction industries), there were 852,000 U.S. partnerships with 3.9 million partners.

${ }^{4}$ Cressy (1996) and Astebro and Bernhard (2003) both report substantial effects on the survival of new firms of the number of owners.
} 
formation (Mason, 2009), but without apparent knowledge of their respective efficacy. Thus, understanding the mechanisms behind partnership formation matters both for economic policy and business strategy.

To illustrate how we will disentangle the selection effects from value added, we develop a model of invention commercialization with business partner selection. Our model describes the choice of an individual deciding whether to commercialize an invention on her own or to form a partnership. Individuals are endowed with both an invention and limited wealth. Partners can provide human and social capital to increase the productivity of capital, and may also relax liquidity constraints. Forming a partnership involves a sunk cost. Partnership formation therefore depends on the partner's potential contribution of human and social capital and the extent to which an inventor is liquidity constrained. The model shows how selection on invention quality and demand for financing can jointly arise.

Our empirical analysis uses data from invention projects through a survey of Canadian individual inventors using the Invention Assessment Program at the Canadian Innovation Center (CIC). The data reveal that in approximately 21 percent of the projects the inventor was joined by business partners. The primary reason for the inventor to create a partnership was to obtain human capital (65\%), followed by obtaining financing (51\%), and social capital (42\%), indicating a broad array of resources provided by partners. These partners take on substantial risk. In our sample the average pre-revenue external investments are approximately $\$ 29,500$ (2003 Cdn $\$$ ), when the average probability of commercialization is 0.11 .

Regression analysis show that there is selection into partnerships based on the quality of the invention and the demand for financing. High-quality assessed invention projects by the CIC were twice as likely to be joined by a partner as the low-quality projects. And the average $R \& D$ expenditures were over four times larger for projects eventually joined by partners than for soloruns. We also test model implications stating that; a) the probability to form a partnership with financing should increase with invention quality, and b) the partnership effect should decline once controlling for the amount of external financing and c) the marginal return to external financing should be less than for internal financing. Regression analysis support all three predictions.

To examine value added we use commercialization success as our key dependent variable: the log of business revenues. Other studies have used business survival, raising of venture capital or time to IPO as proxies for business success. For this sample we believe that commercialization revenues is an appropriate measure of business success as most of these businesses have limited opportunity to raise formal venture capital or be listed on major stock exchanges, and business survival may be capturing the subjective value of staying an entrepreneur. Accounting for selection 
on invention quality in Tobit regressions of commercialization revenues significantly reduces the effect that forming a partnership has on commercialization success, but a significant partnership effect remains.

Three additional mechanisms may explain the remaining partnership effect: The role of commercialization investment, external financing, and labor effort. Indeed, accounting for these mechanisms reduces the partnership effect further. The remaining partnership effect, however, is still economically significant after applying these controls.

We use two alternative approaches to control for additional heterogeneity. In the first approach we control for selection on measurable inventor and invention characteristics into partnerships using a propensity score weighted Tobit model. This further reduces the size of the partnership coefficient. However, the remaining partnership coefficient still represents at least $46 \%$ of the coefficient's original size. At the sample mean, partners' human and social capital thus increases the probability of commercialization between 0.06 and 0.09 percentage points when the probability of commercialization is 0.06 for solo entrepreneurs, and increase expected revenues by at least $29 \%$.

In the second approach we control for unobserved heterogeneity. To do so we test an implication of our model: once controlling for the capital investment, a partner that is said to exclusively provide financing should not provide any further value added to the project. If a partnership effect remains in such a project, it must therefore indicate selection on unobservables. We can thus construct a lower bound on the value added of partner ability. Implementing this specification, we find a lower bound of partner value added providing at least a 0.06 percentage points increase in the probability of commercialization, and at least a $38 \%$ increase in expected revenues. Both approaches thus deliver the same message: the value added of partners' human and social capital is very large.

Our paper is related to those examining the value added of formal venture capital to entrepreneurs and the economy. This literature tries to identify if $\mathrm{VC}$ financing improves business performance and innovation (Kortum and Lerner, 2000; Mollica and Zingales, 2007), and if VCs additional resources (such as a big rolodex) add value to the start-up (see Hellmann and Puri, 2000; Hellmann and Puri, 2002; Hochberg, Ljungqvist, and Lu, 2005; Chemmanur, Krishnan, and Nandy, 2009). Several papers show that the reputation of a VC acts as a signal of the quality of the venture, indicating that some VCs may be selected by entrepreneurs because they add value beyond financing (see Meggison and Weiss, 1991; Hsu, 2004; Sorensen, 2008). Hall and Lerner (2010) summarizes this literature stating that it has been a challenge so far to clearly document value added by early stage investors. ${ }^{5}$

\footnotetext{
${ }^{5}$ The first paper acknowledging the possibility that venture funding and innovation could be positively related to
} 
Closest to our paper is Kerr, Lerner, and Schoar (2010) who empirically demonstrate a positive effect of obtaining angel financing, among angel financing applicants, on survival and access to follow-on funding of high-growth start-up firms using a regression discontinuity approach. Similarly to Kerr et al. (2010), we estimate the relative importance of early stage informal venture capital to inventive projects, and we address the potential endogeneity of financing. Our paper, however, differs from Kerr et al. (2010) in at least four aspects. First, we do not restrict the source of informal venture capital. Second, by using two proxies of pre-partnership invention quality, we control for selection into partnerships based on invention quality and demand for financing. Third, to guide analysis we provide a formal model of the partnering process to identify the precise effects of selection into partnerships, commercialization investments, external financing, labor effort, and value added in the form of human and social capital. Finally, we take a different stand by empirically identifying the marginal effect of the partners human and social capital on both the probability of commercialization and expected commercialization revenues, while also purging estimation from the effects of external financing, and observed and unobserved heterogeneity in two distinct ways.

There is also a large related literature on teamwork efficiency which analyzes bargaining issues and contract design primarily as it applies to team production in large established firms (see review by Lazear and Shaw, 2007). In this paper we abstract away from bargaining issues, which nevertheless might be important.

Our work also contributes to the literature on the choice of entrepreneurship. In a paper also relevant to the subject, Lazear (2005) develops a theory of entrepreneurs as jacks-of-alltrades where he assumes that the entrepreneur must perform all business tasks and the choice of entrepreneurship is a strict function of his worst skill. The model we propose distances itself from Lazear's in that we allow individuals to add partners to obtain the required skills. Furthermore, our work is distinct to Holmes and Schmitz (1990), who develop a theory of entrepreneurship with specialization and business transfers. We focus on the process and benefits of partnerships and, accordingly, we abstract from the possibility that the inventor may instead transfer her invention to others. ${ }^{6}$ Finally, Evans and Jovanovic (1989) studied the degree to which personal wealth provides a binding liquidity constraint for a single individual's choice between entrepreneurship and wage work. We instead focus on individuals that already have an entrepreneurial idea and who may find partners to relax liquidity constraints for commercial entry.

an unobserved factor (e.g., the arrival of technological opportunities, the quality of the venture) was by Hellmann and Puri (2000).

${ }^{6}$ We find only 5 inventors that were able to transfer their idea for cash to another entity. Those 5 are deleted from analysis. 


\section{A model of selection into business partnerships}

The economy is populated by inventors and business partners. Inventors are endowed with a unit of labor, an invention of quality $Q$, and assets $Z .^{7}$ The inventor can use her unit of labor to commercialize the invention. The invention quality and assets are distributed with cdf $F_{Q, Z}$ and are independent. Business partners are also endowed with a unit of time. The partner can use their unit of time to contribute complementary human and/or social capital as well as financing. The partner's social and human capital ability are randomly drawn from a cdf $F_{\beta}$. We assume that both the inventor and partner have an inelastic supply of labor and will therefore spend their unit of time in the venture. Every inventor meets a partner with positive probability. Inventions can be commercialized by the inventor on her own or with a partner. ${ }^{8}$

If the invention is commercialized by the inventor on her own, the profits are $V^{S}=Q K^{\alpha}+$ $r(Z-K)$ where $K$ is the amount of commercialization capital invested in the business, $r$ is the interest rate (i.e., the opportunity cost of capital), and $\alpha \in(0,1)$. The complementarity between the commercialization capital and the invention quality implies that a higher quality of the invention will produce a higher marginal product of capital at all levels of capital. As a result some inventors may have insufficient assets to fully fund the capital investment. Following Evans and Jovanovic (1989), we consider that inventors can borrow against their assets to fund capital investment. If $Z<K$, the inventor is a net borrower, and $r(Z-K)$ is the amount he repays at the end of the period. An inventor with assets $Z$ will be able to borrow an amount up to $(\lambda-1) Z$ and invest up to $K \leq \lambda Z,{ }^{9}$ where $\lambda>1$. Whenever the optimal capital investment is higher than the inventor's borrowing capacity the inventor will be liquidity constrained.

If the invention is commercialized with a partner, the capital is leveraged by $A(\beta)$, the partner's ability. The partner may also provide financing beyond what can be borrowed based on wealth to release an inventor's liquidity constraint. The joint profits then are $V^{P}=A(\beta) Q K^{\alpha}+r(Z-$ $K)-\tau .{ }^{10}$ We constrain $A(\beta) \geq 1$ indicating that partners do not reduce productivity. For

\footnotetext{
${ }^{7}$ In an extended version one may separately introduce the inventor's entrepreneurial ability. Here, $Q$ can be considered representing also the inventor's ability. In the empirical analysis we analyze the robustness of results by allowing entrepreneurial ability to vary in some specifications.

${ }^{8}$ We abstract away from deciding on the number of partners; our stylized partner could therefore also be interpreted as the endowments of a set of partners. We also disregard the case where the inventor directly sells the invention. Our simplified model holds for the majority of partnerships since most partnerships are between two individuals. For example, Ruef, Aldrich, and Carter (2003) shows that in the Panel Study of Entrepreneurial Dynamics, out of 421 start-ups with partners, $74 \%$ had two members, $13 \%$ had three members, $7 \%$ four, and $5 \%$ had five or more. A slightly expanded version of our model would characterize selection of multiple partners by setting the opportunity $\operatorname{cost}$ to $\mathrm{n} \tau$ where $\mathrm{n}$ is the number of partners.

${ }^{9}$ Note that $\lambda Z=Z+(\lambda-1) Z$.

${ }^{10}$ Inventors are assumed to form a partnership rather than hiring employees because it is hard to write employment contracts when commercialization efforts (while observed by the contractual parties) are not verifiable by a third party (Grossman and Hart, 1986).
} 
simplicity we hereon reduce notation to $A$ for partner ability, although $A(\beta)$ is some function of a vector of human and social capital. Partners' ability contribute towards a higher productivity of capital for a given level of invention quality. ${ }^{11}$ An additional benefit of a partnership is that business partners can contribute external financing. The parameter $\tau$ is a sunk cost to form a business partnership. We interpret it as the partner's opportunity cost to join the partnership. For simplicity, we assume that invention quality, inventor wealth, and the partner's ability are observable by the two parties. ${ }^{12}$ This assumption together with an inelastic supply of labor implies that there will be no use of convertible features in the contract between the inventor and the business partner. ${ }^{13}$ These assumptions were motivated by the distinctive objectives and modes of operation of informal venture capital. Informal venture capital investors, generally, do not rely on traditional control mechanisms, such as board control, staging or contractual provisions. They typically make only a few investments at a time and tend to invest substantially smaller amounts than VCs, invest their savings on their own, and they often spend time 'hands-on' in the business. In addition, we assume that partners are sufficiently financially endowed that partnerships can reach the unconstrained level of capital investment that maximizes profits. This final assumption simplifies the analysis considerably.

An inventor chooses to form a business partnership if the profit from that, $V^{P}$, is higher than the profit from a solo-entrepreneurship, $V^{S}$, assuming contracting is efficient. ${ }^{14}$ Profits are evaluated at the capital investments that maximizes their respective profits subject to liquidity constraints. Efficient contracting implies that as long as forming a partnership is mutually beneficial, our results do not depend on how profits are split. If the inventor is not liquidity constrained

\footnotetext{
${ }^{11}$ An alternative interpretation is that partners leverage the quality of the invention. Both interpretations are possible, adopting the alternate does not change the comparative statics that follow.

${ }^{12}$ Allowing for asymmetric information in our model at the time of partnership formation will not change the qualitative results concerning selection on invention quality and demand for financing.

${ }^{13} \mathrm{~A}$ more general framework including some elements such as persistent asymmetric information, unobserved effort, and multiple rounds of financing -albeit without selection- has been analyzed in Chemmanur and Chen (2006) and Repullo and Suarez (2004). Both papers study the double-sided moral hazard problem on the part of both the investor and the entrepreneur. The optimal contracts in both models predict the use of convertible features either to provide incentives to the entrepreneur (Repullo and Suarez, 2004) or the investor (Chemmanur and Chen, 2006). Interestingly, Chemmanur and Chen's analysis predicts that angel financing contracts are less likely to incorporate convertible features compared to formal VC contracts.

${ }^{14}$ Efficient contracting implies that we are agnostic about how the surplus is split. That is, the incentive to form a partnership for the inventor will be the same independently on how the surplus is split. There is no strictly preferred way to determine the division of surplus and, while it has sometimes been derived from an explicit bargaining game, it has been more common to assume that each party's share of the surplus is given exogenously. For example, in one well-known model of teamwork production, Kremer (1993, p. 585) simply notes that "the division of a firm's output among its heterogeneous workers [is] determined by a complex bargaining problem." Our model could consider potential inefficiencies associated with moral hazard problems of partnership production (see Holmstrom, 1982), but since we have no data on partnership structure, predictions from such an extension would not be testable. Instead, we assume that all inefficiencies associated with partnerships are scaled by the parameter $\tau$.
} 
(i.e., $\left.Q \leq \frac{r}{\alpha A}(\lambda Z)^{(1-\alpha)}\right)^{15}$, the difference between $V^{P}$ and $V^{S}$ represents extra profits associated with a higher productivity of capital as a result of the partner's ability. Unconstrained partnerships are formed exclusively to add human and/or social capital. If the inventor is liquidity constrained, the extra profits represent both higher productivity of capital (whenever partner's ability is provided) and the effect of relaxing liquidity constraints, increasing the commercialization investment to its optimal level. These partnerships may be formed to add human and/or social capital, or to obtain external financing.

Figure 1: The Decision to Partner as a function of A and Q given fixed inventor assets Z

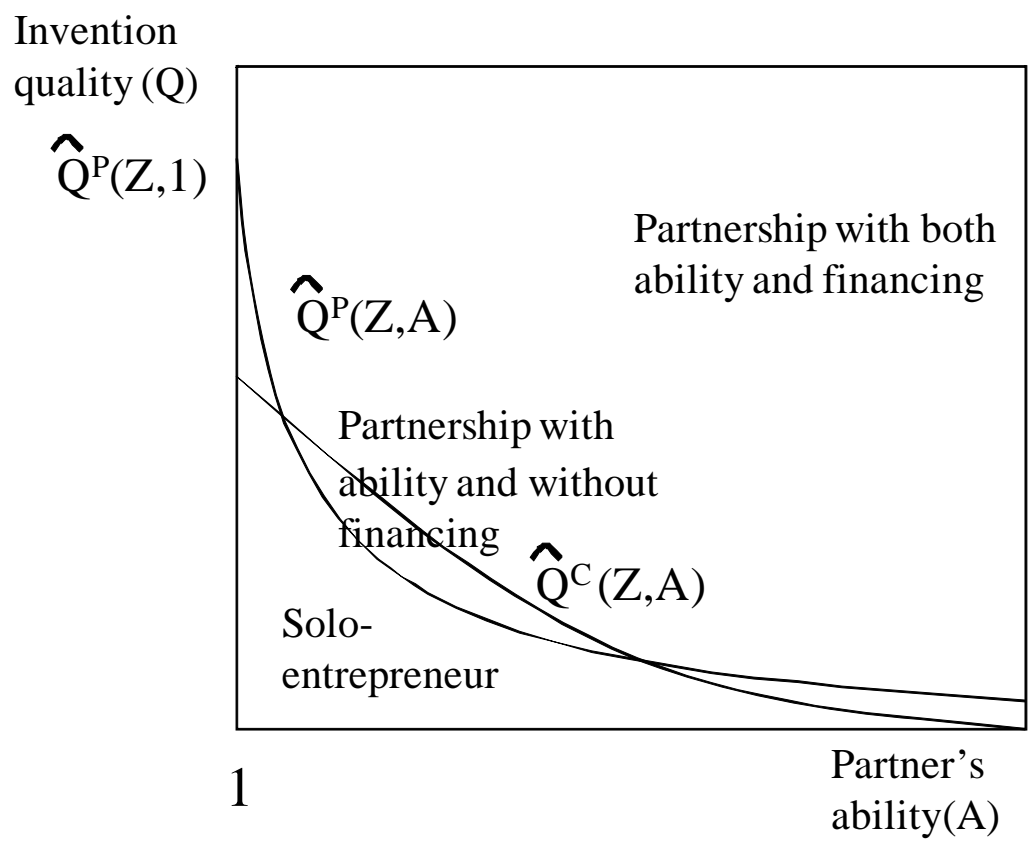

The partnership optimal decisions are illustrated in Figure 1 where invention quality $(Q)$ is plotted against partner ability $(A)$ for a given level of assets. ${ }^{16}$ The figure is divided into two main regions - solo-entrepreneurship and partnership - by the threshold $\widehat{Q}^{P}(Z, A)$, where $\widehat{Q}^{P}$ is the value of $Q$ where $V^{P}=V^{S}$. Given a partner's ability and the inventor's assets, the inventor will form a partnership if and only if the invention quality is above the threshold $\widehat{Q}^{P}(Z, A)$, which implies that $V^{P}>V^{S}$. The threshold $\widehat{Q}^{P}(Z, A)$ decreases with the partner's ability indicating that the higher the ability of the partner, the lower the invention quality needed for an inventor

\footnotetext{
${ }^{15}$ Note that $\frac{r}{\alpha A}(\lambda Z)^{1-\alpha}$ is the level of invention quality such that the inventor's commercialization investment that maximizes the profits in a partnership is equal to the inventor's investment capacity, i.e., $\left(\frac{\alpha Q}{r}\right)^{1 /(1-\alpha)}=\lambda Z$. See appendix for more details.

${ }^{16}$ The formal proofs of the following results are in the appendix.
} 
to be indifferent between commercializing the invention with or without a partner.

A prediction that follows from this model is that when invention quality increases, the probability to form a partnership increases. This is because a higher invention quality facilitates the amortization of the sunk costs to form a partnership. As a result, we should expect a positive correlation between pre-partnership invention quality and inventions commercialized in partnerships. A second prediction from the model is that the higher the ability of the partner that the inventor meets the higher the probability of partnership. This implies that conditional on a partnership being formed, the average ability of a partner should be strictly higher than the ability of the average potential partner. Both predictions are probabilistic because there is a probability of meeting a partner and there is ex ante uncertainty about the ability of the partner. These predictions have important implications for the estimation of value added. There will be selection into partnerships based on invention quality, and there will be selection into partnerships based on the partner's ability. Estimation of the marginal impact of the partner's ability on commercialization success must therefore control for the quality of the invention, and can only be interpreted as an average treatment-on-the-treated effect (Heckman, 1979).

The region with partnership formation is further divided into two areas by the threshold $\widehat{Q}^{C}(Z, A)$ - partnerships with financing and partnerships without financing. $\widehat{Q}^{C}$ defines the quality level above which the inventor is liquidity constrained. The threshold $\widehat{Q}^{C}$ decreases with the partner's ability indicating that the higher the partner's ability the lower is the invention quality above which an inventor is liquidity constrained. Partnerships with ability but without financing are located in the region above $\widehat{Q}^{P}$ and below $\widehat{Q}^{C}$ in Figure 1. These partnerships do not require a partner for financing reasons, but the partner's contribution of human and/or social capital outweighs the cost of partnering. There are two characteristics about these partnerships that are worth noticing. First, partnerships with ability but without financing exist only for intermediate levels of invention quality; for higher levels of invention quality there will always be external financing as the inventor's liquidity constraint will eventually bind; and for lower levels of invention quality a partnership may only be profitable when external financing releases liquidity constraints (inventor's assets are low) and therefore partners will provide both ability and financing. Second, for the intermediate levels of quality, decreasing invention quality further may temporarily increase the proportion of partnerships with no financing while the overall proportion of partnerships may decrease, as can be seen in Figure 1. The explanation is that the relative benefit of the contribution of partners' ability holds up better than the drop in value added of external financing as invention quality diminishes.

Partnerships with both ability and financing are characterized by inventions that range from 
high to low levels of invention quality. The partnerships with higher level of invention quality involve external financing because the inventor's liquidity constraints are more likely to bind. Instead, partnerships of low invention quality may only be profitable when inventor's assets are low and therefore partners must provide both ability and financing. If the demand for external financing originates from these lower quality inventions, the selection effect on demand for financing will be less. These results suggest that to assess the importance of selection on demand for financing we may compare the mean invention quality in partnerships with both ability and financing against partnerships with ability but without financing. If the mean quality in partnerships with both ability and financing is lower than the quality in partnerships with ability but without financing, then the proportion of inventors with sufficiently low assets in the economy will be large and the selection on demand for financing will be less.

Finally, it is possible that if invention quality is sufficiently high a partner without ability may join simply to release credit constraints. Partnerships that provide only financing are located at the top left corner of Figure 1.

To summarize this discussion, there will be three types of partnerships; those where partners only bring financing, those where partners provide both ability and financing, and those where partners only provide ability. A first testable prediction of the model was that when invention quality increases, the probability to form a partnership increases. This implies selection on quality. The second prediction was that the higher the ability of the partner that the inventor meets the higher the probability of partnership. This implies selection on partner ability. A third prediction was that the probability to form a partnership to obtain financing increases with invention quality. This prediction implies selection on demand for financing. However, we also showed that the mean invention quality in partnerships with both ability and financing may be lower than for partnerships with ability and without financing. This could happen if the proportion of inventors with sufficiently low assets in the economy is large and would imply that selection on demand for financing would be less. ${ }^{17}$

\footnotetext{
${ }^{17}$ If we for the moment assume uniform distributions of assets and invention quality in the inventor population, and a uniform distribution of partner ability, the most likely type of partnership is that where partners bring both financing and abilities. However, skew or bimodal distributions of quality, assets or ability in the economy may temper this prediction. An additional conclusion from the model is that the pool of solo-entrepreneurs will consists of two types; those with low quality inventions which are not liquidity constrained and those with higher quality which are liquidity constrained but which did not find a suitable partner. The fraction of liquidity constrained solo-entrepreneurs as well as the fraction of partnerships varies across economies as a function of the preponderance of potential partners (with financing and abilities) in the economy, and the distribution of invention quality and assets in the inventor population.
} 


\section{Data}

We focus our empirical analysis on a sample of independent inventors; that is, individuals who decide to develop inventions outside their regular employment duties. Many inventors may not have great entrepreneurial or business skills and may lack the financial capital necessary to commercialize their inventions. Further, they may lack the benefits of working in a large organization in terms of access to a multitude of internal resources such as a lab, funding, skilled colleagues, and an established marketing and distribution network. They may thus find it particularly useful to have others join them in their commercialization efforts. A construction business, corner store, personal service, or restaurant (the most common start-ups), may not require large up-front investments, but commercializing new products involve using significant business skills and capital investments. Studying independent inventors should thus likely provide an excellent opportunity to examine the role of informal venture capital, partnership mechanisms, and their outcomes.

However, it is costly, given their scarcity, to find independent inventors among the general population. To economize on search costs, we therefore use a list of independent inventors, self-identified through their use of the services of the Canadian Innovation Centre (CIC). The assessment results in an overall recommendation that is either positive or negative. Our sample frame consists of inventors that had asked the CIC to evaluate their inventions between 1994 and 2001. Of these, we had current addresses for 1,770 which we contacted by surface mail in 2004. We were then able to contact 934 by telephone, and from these we obtained 830 telephone surveys. All data except the invention evaluations are self-reported. We remove 53 partially answered surveys and 5 observations where the IP was sold or licensed, leaving 772 observations for analysis. ${ }^{18}$ Missing item responses were imputed five times assuming data were Missing At Random (MAR) using a switching regression approach described in van Buuren et al. (1999), where missing data were randomly replaced conditional on observed data and survey structure. Means, coefficient estimates and standard errors are subsequently computed over five complete datasets using the formulae in Little and Rubin (1987, equations 12.17-12.20). ${ }^{19}$ Pseudo- $R^{2}$ 's are provided for one of the five samples as an indication of absolute levels.

The data primarily contains information on pre-CIC research and development (R\&D) expen-

\footnotetext{
${ }^{18}$ For survey details see Astebro, Jeffrey, and Adomdza (2007).

${ }^{19}$ In multiple imputation, missing values for any variable are predicted using existing values from other variables. The predicted values replace missing values, resulting in a full data set. This process is performed multiple times. Standard statistical analysis is performed on each imputed data set. Results are then combined. Multiple imputation restores not only the natural variability in the missing data, but also incorporates the uncertainty caused by estimating missing data. Uncertainty is accounted for by creating different versions of the missing data and observing the variability between imputed data sets. For a further introduction to multiple missing data imputation see Graham and Hofer (2000).
} 
ditures, pre-partnership invention quality assessment by the CIC, post-CIC commercialization expenditures, a dummy for the creation of a partnership to commercialize the invention, three non-exclusive dummies for the type of capital partners bring (human capital, social capital, and financing), the amount of external financial capital, whether or not the invention was commercialized, total commercialization revenues, and year and industry classification codes. There are also sundry inventor and invention characteristics in the survey that we employ when computing partnership propensity scores.

\subsection{Summary statistics}

The modal inventor age is 45-54 and the modal educational attainment is high school, although about $26 \%$ of the inventors had some professional or graduate education. Only $16 \%$ of the inventors reported they were unemployed, home-makers, retired, disabled, or on sick leave during the time that they were developing their focal invention. Most $(58 \%)$ were full-time employees, while $32 \%$ were self-employed when developing their invention (multiple answers possible). To understand the composition of the inventor sample better, we drew a comparison sample from the general Canadian population. ${ }^{20}$

While the identification of inventors relies on a specific, focal, invention submitted to the CIC it does not imply that the individuals are predominantly one-shot inventors. To the contrary, the sample is dominated by long-term serial inventors. Fifty-three percent of them had spent six or more years developing inventions, and $75 \%$ had worked on more than one invention. Eleven percent developed the invention as part of their normal duties at work. Twenty-six percent were stimulated by something at work, a majority of which $(73 \%)$ were not required to innovate at work. Descriptions of some inventions reveal most to be "user-driven". The sources of invention are thus quite varied.

With regards to the inventions, $21 \%$ were rated as of high quality by the CIC and given a positive recommendation, suitable to develop further at least as a part-time effort. The other

\footnotetext{
${ }^{20}$ We queried a sample of 300 Canadians from the general population based on sampling quotas for province, work experience, and gender, to reflect similarities in the aggregate with the inventors on these three variables. The combined samples contains unusually high fractions reporting that they are or have been self-employed (63 percent), or have owned a business (60 percent). The rates of entrepreneurship are much higher for the inventor sample than for the general population sample: 72 percent of the inventor sample report current or prior self-employment, compared with 43 percent of the general population sample; 67 percent of the inventor sample report current or prior business ownership compared with 43 percent of the general population sample. Overall, the average number of businesses that have been owned is 1.20; again, the figure is much higher for the inventor sample (1.49) than for the general population sample (0.69). Note also that individuals in the more entrepreneurial inventor sample are more likely to have come from an entrepreneurial family. The two samples otherwise do not differ much on comparable variables such as age, education, experience, gender, marital status, managerial experience and business experience. For further details see Astebro and Thompson (2011).
} 
$79 \%$ were deemed of low quality and inventors were recommended to stop further development. Most numerous were sports/leisure products (28\%), followed by $16 \%$ security or safety applications, $14 \%$ automotive, $14 \%$ medical or health, and $13 \%$ which had environmental or energy applications. Inventions involving high technology (9\%) and industrial equipment (14\%) were also relatively frequent. Successful consumer-oriented inventions included a new milk container design, a washable sanitary pad, and a home security light timer that imitates typical use. Other inventions had business applications. These inventions included an aligner and printer for photographic proofs, a tractor-trailer fairing that enhances fuel efficiency, a re-usable plug to insert in wooden hydroelectric poles after testing for rot, and a computerized and mechanically integrated tree harvester. Thus, the inventions varied substantially in technological complexity and market potential. The median invention development effort was performed in 1997, and 95\% of respondents had attempted to develop their focal invention before 2003.

The pre-commercialization investments in the inventions reveal to be far larger than in the ordinary start-up. For example, the 1992 Characteristics of Business Owners database report that the majority of U.S. start-ups (approximately 60\%) were started or acquired with no cash outlay or with less than $\$ 5,000$ (U.S. Department of Commerce, 1997.) In contrast, the average R\&D investment for the inventors is approximately Cdn. $\$ 22,500$ and the additional commercialization investment is another Cdn. $\$ 24,800$ (2003 values). Nevertheless, investments in these projects at the same time appears somewhat less than those undertaken by 'business angel networks'. For example, Wiltbank and Boeker (2007) report the average investment size per project (including follow-on investments) by business angel networks to be $\$ 191,000$ (median investor contribution $\$ 50,000)$, while Wiltbank (2009) report an average investor contribution of $£ 42,000$. Note that the samples of projects with business angel investors are constructed conditioned on business angel investments being positive, while our sample does not have this restriction.

\section{Partnerships and the commercialization of inventions}

We first report some descriptive statistics on partnerships and solo-entrepreneurs. In approximately $21 \%$ of the projects the inventor was joined by someone to commercialize the invention. The primary reason for the inventor to create a partnership was to obtain human capital (65\%), followed by obtaining financing (51\%), and social capital (42\%). ${ }^{21}$ Figure 1 suggested four po-

\footnotetext{
${ }^{21}$ We asked the inventor "Did you ever team up with other people trying to commercialize the invention?", if yes, we further inquired: "Why did you team up with other people?" with the following options read: "You needed to have your skills complemented by their skills", "They had contacts that were useful", "You needed the capital they provided", "They had resources that were useful (land, equipment, plant)" and "Other". In analysis the two categories prior to "other" are collapsed into one. The questions imply that there is some form of matching where
} 
tential choices for an inventor: no partnership; with only financing provided; partnership with financing and ability provided; and finally partnerships with only ability provided by the partner. Table 1 can be used to compute the proportions of these outcomes. As stated above, $79 \%$ are without a partnership. Among the partnerships, in $16 \%$ of the cases there were only financing provided, in $51 \%$ there were both financing and ability provided by partners, and in $45 \%$ of the partnerships there were only ability provided.

The fact that a significant number of inventors are joined by someone to commercialize their invention suggests that there may be benefits to partnership. Indeed, we find that working with partners is positively correlated with the probability that inventions are commercialized. Table 1B shows that partnerships have a probability of commercialization of 0.30 , which is about five times larger than that of projects run by solo-entrepreneurs (0.06). The presence of partners is also positively correlated with revenues. Projects run by solo-entrepreneurs had mean present value of revenues of $\$ 24,196$; mean revenues from projects run by partnerships were approximately ten times as much; $\$ 232,397$. While solo entrepreneurship dominates the data there appears to be enough variation to examine partnership selection mechanisms and benefits. Importantly, not all partners provide financing indicating a potential value added effect through human and/or social capital.

\subsection{Selection into partnership}

Selection on invention quality The theoretical model predicts a positive correlation between pre-partnership invention quality and the probability of partnership formation. To investigate selection on invention quality, we classify inventions into two categories; high quality inventions will be those with a CIC positive assessment, the rest of the inventions are deemed of low quality. It is immediately apparent that partners are more likely to join inventors with high quality inventions, as shown in Table 1B. Partnerships are twice more likely to have high quality inventions than solo-entrepreneurs, 35 percent versus 18 percent. Stated differently, 34 percent of inventions rated as high quality were eventually joined by a partner, while only $17 \%$ of inventions with low quality were joined by a partner. We have also classified the quality of the inventions using the inventor's own research and development (R\&D) expenditures prior to the CIC assessment and formation. ${ }^{22}$ Partners were more likely to join inventors with higher $\mathrm{R} \& \mathrm{D}$ expenditures. The average $\mathrm{R} \& \mathrm{D}$ expenditures by the inventors that were eventually joined by partners was $\$ 90,364$; the solo-entrepreneurs spent on average $\$ 4,725$. To control for varying

the partner provides something which the inventor does not have.

${ }^{22}$ We separate between the idea creation and commercialization phase by the date of the CIC assessment. 
Table 1: Commercialization, Invention Quality, $\mathrm{R}$ and D Expenditures and Revenues by Soloentrepreneurs and Teams.

The sample consists of 772 inventions from inventors that had asked the Canadian Innovation Center (CIC) to evaluate their inventions between 1994 and 2001. The table is divided into three parts. Panel A describes the percentage of inventions that were commercialized in partnerships, and the percentages of partnerships where partners provided only financing, both financing and ability, or only ability. Panel B presents characteristics of inventions commercialized by partnerships and solo-entrepreneurs. These characteristics are: the percentage of inventions with a positive CIC assessment; the probability of commercialization; and the means of the $\mathrm{R}$ and $\mathrm{D}$ expenditures, the commercialization investment, and the commercialization revenues. Panel $\mathrm{C}$ presents characteristics of projects conditional on commercialization. All data are in Cdn 2003 dollars. Each missing item response has been imputed five times following van Buuren et al. (1999). Means are computed using the formulae in Little and Rubin (1987).

A. Percentage of projects with partnerships and contributions by partners

$$
\text { Percentage partnerships (\%) } \quad 21.0
$$

Contributions among partnerships (\%)

$$
\text { Only financing } \quad 15.6
$$

Both financing and human/social capital $\quad 35.6$

$$
\text { Only human/social capital } \quad 45.6
$$

\begin{tabular}{|c|c|c|c|}
\hline & All & Partnership & $\begin{array}{c}\text { Solo- } \\
\text { entrepreneur }\end{array}$ \\
\hline $\begin{array}{l}\text { Percentage with } \\
\text { positive CIC review (\%) }\end{array}$ & 21.5 & 35.5 & 17.8 \\
\hline $\begin{array}{l}\text { Mean R\&D expenditures }(\$) \\
\text { by inventor prior to the CIC review }\end{array}$ & 22,518 & 90,364 & 4,725 \\
\hline $\begin{array}{l}\text { Mean commercialization } \\
\text { investment }(\$)\end{array}$ & 24,823 & 70,690 & 12,792 \\
\hline $\begin{array}{l}\text { Mean commercialization } \\
\text { revenues }(\$)\end{array}$ & 67,432 & 232,397 & 24,196 \\
\hline Probability of commercialization (\%) & 10.9 & 29.9 & 5.9 \\
\hline \multicolumn{4}{|c|}{ C. Characteristics of projects conditional on commercialization } \\
\hline $\begin{array}{l}\text { Percentage with } \\
\text { positive CIC review (\%) }\end{array}$ & 49.3 & 55.0 & 41.7 \\
\hline $\begin{array}{l}\text { Mean R\&D expenditures }(\$) \\
\text { by inventor prior to the CIC review }\end{array}$ & 166,009 & 282,354 & 10,882 \\
\hline $\begin{array}{l}\text { Mean commercialization } \\
\text { investment }(\$) \\
\text { Mean commercialization }\end{array}$ & 110,343 & 169,732 & 31,158 \\
\hline revenues $(\$)$ & 619,739 & 776,238 & 411,073 \\
\hline
\end{tabular}

B. Characteristics of projects unconditional on commercialization 
Table 2: Probit Regression Analysis of Partnership

The sample consists of 772 inventions from inventors that had asked the Canadian Innovation Center (CIC) to evaluate their inventions between 1994 and 2001. The dependent variable is partnership, a dummy variable taking the value 1 if an innovation was commercialized as a partnership, 0 otherwise. The independent variables are "Positive", a dummy variable taking the value 1 if the CIC assesment was positive, 0 otherwise; and "R and D expenditures", the natural logarithm of R and D expenditures. All data are in Cdn 2003 dollars. All regressions include dummy variables controlling for the project's industry, and the year the invention was assessed by the CIC. Standard errors in parenthesis. $* * *, * *$ or $*$ mean the coefficient is significant at the 1 percent, 5 percent, or 10 percent level, respectively. Each missing item response has been imputed five times following van Buuren et al. (1999). Coefficients and standard errors are computed using the formulae in Little and Rubin (1987).

\begin{tabular}{lccc}
\multicolumn{4}{l}{ Parameter estimates of effects of invention quality } \\
\hline \multirow{2}{*}{ Positive } & $0.397^{* * *}$ & & 0.211 \\
& $(0.130)$ & & $(0.142)$ \\
R\&D expenditures & & $0.080^{* * *}$ & $0.071^{* * *}$ \\
& & $(0.016)$ & $(0.017)$ \\
\hline Pseudo $R^{2}(\%)$ & 0.06 & 0.08 & 0.08 \\
$\mathrm{~N}$ & 772 & 772 & 772 \\
\hline \hline
\end{tabular}

capital requirements by technology and for varying costs of capital we include industry and year dummies in a regression of the probability of formation on invention quality. Estimates survive the inclusion of these industry and year controls (see Table 2). The Table also reveals that inventors' $\mathrm{R} \& \mathrm{D}$ expenditures were correlated with the CIC assessments.

Selection on demand for financing An additional reason for why partners join inventors is to provide external financing. The model provides several predictions concerning the interplay of external financing and formation. A first prediction is that the probability to form a partnership to obtain financing increases with invention quality. Using the same quality indicators and controls as before as predictors, Table 3 presents Probit regressions with a dummy $=1$ if a partnerships was formed to obtain financing, and zero otherwise. The table shows support for this prediction. It appears that most of the invention quality variation that determines partnership financing is best captured with pre-partnership R\&D expenditures.

Another prediction refers to the invention quality where partners provide both ability and financing versus the quality where partners provide only ability. According to our theory, partnerships with both ability and financing can have lower average invention quality than partnerships with only ability only if the proportion of inventors with low assets is high. Data show that partnerships with both ability and financing indeed have a lower proportion of positive CIC as- 
Table 3: Probit Regression Analysis of Partnership with Financing

The sample consists of 772 inventions from inventors that had asked the Canadian Innovation Center (CIC) to evaluate their inventions between 1994 and 2001. The dependent variable is partnership with financing; a dummy variable taking the value 1 if an innovation was commercialized by a partnership with financing, 0 otherwise. The independent variables are Positive; a dummy variable taking the value 1 if the CIC assesment was positive, 0 otherwise; and the natural logarithm of $\mathrm{R}$ and $\mathrm{D}$ expenditures. All data are in Cdn 2003 dollars. All regressions include dummy variables controlling for the project's industry, and the year the invention was assessed by the CIC. Standard errors in parenthesis. $* * *, * *$ or $*$ mean the coefficient is significant at the 1 percent, 5 percent, or 10 percent level, respectively. Each missing item response has been imputed five times following van Buuren et al. (1999). Coefficients and standard errors are computed using the formulae in Little and Rubin (1987).

\begin{tabular}{lccc}
\multicolumn{4}{l}{ Parameter estimates of effects of invention quality } \\
\hline \multirow{2}{*}{ Positive } & & & -0.029 \\
& 0.125 & & $(0.165)$ \\
R\&D expenditures & $(0.152)$ & $0.055^{* * *}$ & $0.057^{* * *}$ \\
& & $(0.019)$ & $(0.021)$ \\
\hline Pseudo $R^{2}(\%)$ & 0.05 & 0.06 & 0.06 \\
$\mathrm{~N}$ & 772 & 772 & 772 \\
\hline \hline
\end{tabular}

sessments (30\%) and R\&D expenditures (Cdn \$18,775) than partnerships with only ability (41\% and Cdn $\$ 177,025$, respectively). The differences are statistically significant (t-tests of differences in proportions and means are 3.32 and 3.60, respectively.) This result suggests that the proportion of inventors with low assets may be large. It implies that selection on demand for financing may be less since the demand for financing may be primarily from lower quality inventions. Once we analyze value added we can test additional predictions relating to the demand for financing.

\section{The value added of partners' ability}

To study the contribution of partners in the commercialization of inventions we adopt the following econometric specification:

$$
y_{i}=\left\{\begin{array}{ccc}
y_{i}^{*} & \text { if } & y_{i}^{*}>0 \\
0 & \text { if } & y_{i}^{*} \leq 0
\end{array}\right\}
$$

with $y_{i}^{*}$ as a latent variable indicating commercialization success, and

$$
y_{i}^{*}=\alpha q_{i}+\beta d_{i}+\delta X_{i}+\mu_{j}+\tau_{t}+e_{i}
$$

where $y_{i}$ is the $\log$ of commercialization revenues; $q_{i}$ is unobserved (to the econometrician) invention quality; $d_{i}$ is a dummy that equals one if a partnership was formed to commercialize 
invention $i ; X_{i}$ represents regressors that vary across inventions, and $e_{i}$ is a normally distributed zero mean residual component. The terms $\mu_{j}$ and $\tau_{t}$ correspond to industry and CIC application year effects as implemented by a set of dummy variables, and $\beta$ captures the effect of partner's ability on the commercialization revenues conditional on a partnership being formed. ${ }^{23}$ We use the log form to allow for multiplicative effects of inputs as posited by our theoretical model.

Table 4 reports the effect of forming a partnership and control variables on the latent variable $y_{i}^{*}$. We use a Tobit model as there are a large number of inventions that are never commercialized and have zero revenues. ${ }^{24}$ To provide intuition, we use a standard decomposition technique of the coefficient $\beta$ into the marginal effect on the probability of commercialization, and the marginal effect on expected log revenues, both estimated at sample means (see e.g. McDonald and Moffitt, 1980). ${ }^{25}$ The first column (Model 1) shows the estimated coefficient for the partnership dummy controlling for industry and year effect. Joint $t$-tests indicate that industry dummies $(t=1.74)$ and year dummies $(\mathrm{t}=1.70)$ are only marginally significant. After controlling for industry and year dummies the size of $\beta$ is 15.25. Taking this value and evaluating the marginal effects of partnership at the mean of the sample imply that an invention project run as a partnership has approximately a 0.22 greater probability of commercialization than one run by a solo-entrepreneur, and its expected revenues are eight times higher than a solo-entrepreneur project. (Since the controls are only marginally significant the gross differences in Table 1B are quite similar; 0.24 and 9.6, respectively.)

The positive correlation between commercialization success and partnership formation has to be interpreted with caution. We previously showed that partners are more likely to join inventions of higher quality and that the demand for financing depends on invention quality and thus also determines partnership formation. Both findings indicate that the partnership coefficient in Column 1 is endogenously determined and likely upwards biased.

We therefore add two proxies to account for selection based on invention quality: the CIC assessment and the log of R\&D expenditures. The second column in Table 4 (Model 2) shows

\footnotetext{
${ }^{23}$ See Proposition 4 in the appendix for proof that $\beta$ must be interpreted as a treatment-on-the-treated effect.

${ }^{24}$ We also experimented with a Heckman selection specification, but we could not find a variable that could be reasonably assumed to affect the probability to commercialize but not revenues conditional on commercialization. Without an exclusion restriction estimations were very unstable or did not converge.

${ }^{25}$ Consider the following Tobit model. Let the dependent variable be $y=y^{*}$ (if $y^{*}>0$ ) and $y=0$ (if $\left.y^{*} \leq 0\right)$, and the latent variable $y_{i}^{*}=\beta X+e_{i}$. The marginal effect on the observed log of expected revenues $y$ is $\frac{\partial E(y \mid X)}{\delta x_{k}} \beta_{k} \Phi\left(\frac{X \beta}{\sigma}\right)$, where $x_{k}$ is a regressor of interest, $\bar{X}$ is a matrix of the sample means of the regressors, $\beta_{k}$ is the corresponding Tobit estimated coefficient of the regressor $x_{k}$, and $\Phi$ is the cdf of the standard normal distribution. If $x_{k}$ is a dummy, the marginal effect is the difference between the difference of the predicted values of of the dummy evaluated at the sample mean of the rest of the regressors. Because our dependent variable is the log of revenues, the marginal effect of partnership in revenues can be approximated by exponentiating the marginal effect of partnership on the $\log$ of revenues.
} 
that the effect of partnership formation on expected commercialization success then decreases from 15.25 to 11.68 , a 23 percent reduction. The test indicates that there is clear selection on project quality into partnerships. However, the partnership coefficient still remains significant and large. At the sample means, partnerships are associated with an increase in the probability of commercialization of 16 percentage points, and an increase in the expected revenues by a factor of 3.5. The large magnitudes of these effects indicate additional partnership effects.

Two additional mechanisms may explain the remaining partnership effect - the role of commercialization investments and external financing. Our theory suggests that optimal commercialization investments should increase whenever the partner's ability increases the productivity of capital. If partner's ability increases the productivity of capital, controlling for the commercialization investment should account for the part of the partnership effect that causes an increase in the optimal investment level. In addition, the amount of external financing provided by partners should capture the partnership effect on revenues from relaxing liquidity constraints. Unfortunately, due to survey structure we cannot simultaneously identify these two effects. ${ }^{26}$ We therefore run two regressions where we first analyze the impact of commercialization investments and then analyze the impact of external financing.

In Model 3 of Table 4 we analyze the effect of commercialization investments. The third column adds the natural logarithm of post-partnership commercialization investments; the sum of all cash provided both by the inventor and external financiers to commercialize the invention after the formation of a partnership. The results show that the commercialization investment is affected by partners contributing ability because the partnership coefficient declines significantly (35.5\%) when adding the commercialization investment. But while the introduction of commercialization investment reduces the partnership coefficient considerably, the partnership effect remains positive and statistically significant. For instance, evaluating the effects of partnerships at the mean of the sample, partnerships increase the probability of commercialization by 8 percentage points, and increase expected revenues by $65 \%$. Another noteworthy results is that both the quality indicators diminish in size and significance once we control for commercialization investment. The reason is that the commercialization investment is also endogenous to project quality: optimal investments increase with invention quality.

\footnotetext{
${ }^{26}$ The survey enquired: 1 . First, we would like to know how much money was spent on developing XX. Include all costs for product development, marketing research, making of prototypes, etc. How much did you spend before you contacted the CIC for an evaluation? 2. How much did you spend after you contacted the CIC for an evaluation? 3. I will now read a list of sources of funds that you may have used to pay for the costs of developing your invention. Please tell me for each source whether you have actually used it or not. 4. Consider the total amount of money you have spent on this invention so far. How large a proportion of this amount was your own money? These data allow us to identify either the effect of commercialization investment (using question 2) or external financing (using question 4).
} 
To examine whether inventors are liquidity constrained and the degree to which partners relax these liquidity constraints, in Table 5 we separate between the natural logarithm of the inventor's cash contribution and the natural logarithm of the sum of all cash contributions by all external financiers. ${ }^{27}$ A first result from this analysis is that the size of the coefficient for external financing is almost four times lower than the coefficient for own financing in Model 3. This result is consistent with the idea that inventors are capital constrained. If they were not constrained the coefficients for internal and external financing should be equal. ${ }^{28}$ Thus, selection into partnerships to release liquidity constraints is likely to occur. External financing is also positively correlated with the partnership effect, but not very much. Quantitatively, the partnership coefficient is reduced from 10.28 (in model 2) to 9.26 (in model 3), a reduction by $10 \%$. The results indicate that partners may often not be the main external financier.

Our theoretical model assumed that labor supply was inelastic both for the inventor and the partner. But it is possible that labor may be supplied elastically. The inventor may for example be trading off time in the venture with working part-time as an employee and the partner may be investing in several ventures at the same time. We therefore relax the assumption of inelastic labor supply in Model 4. In particular, we inquired about the sum of the number of hours provided by the inventor and all partners post CIC evaluation to commercialize the invention. Including the $\log$ of this number (with log of zero hours set to zero) will allow us to approximately isolate partner ability from hours of input by the partner. Results are reported in Model 4 in Tables 4 and 5 . Controlling for labor inputs, the partnership coefficient drops by $0 \%$ in Table 4 and $5 \%$ in Table 5. The low conditional correlation between the partnership dummy and total hours indicate that it is the inventor whom perform the majority of commercialization efforts, and that the main contribution by partners is skills, rather than hours. However, the magnitudes of the other parameters generally drop, indicating that labor efforts are positively correlated with invention quality, total commercialization investments, and the amount of external financing. Nevertheless, the partnership coefficient remains significant and large.

Whatever is left of the partnership coefficient after accounting for selection on quality, commercialization investment, labor supply, and external financing can be attributed to the partner's ability, but as well to measurement error and model mis-specification. In the next two subsections we therefore attempt to further control for selection on inventor-invention characteristics, selection on unobservables and measurement error to isolate the effect of partner ability on com-

\footnotetext{
${ }^{27}$ All others may be for example banks, family, friends, business partners, universities as well the government. Due to survey structure we could not separate the investments between these external suppliers of capital.

${ }^{28}$ This result is consistent with the finding that smaller and younger firms have higher growth-cash flow sensitivities than larger and more mature firms (see e.g. Fazzari, Hubbard, and Peterson, 2000).
} 
mercialization success.

\subsection{Accounting for selection on observables}

We start by controlling for selection into partnerships on observable inventor characteristics using a propensity-score weighted model described by Hirano, Imbens, and Ridder (2003). ${ }^{29}$ Woolridge (2007) discuss a related approach, but Hirano et al.'s method may produce more efficient estimates. We estimate the propensity to form a partnership with logistic regression using as predictors the previously used variables: Positive, pre-partnership R\&D expenditures, industry and year dummies, as well as a range of additional pre-determined pre-partnership inventor and invention characteristics to calibrate the propensity to form a partnership. ${ }^{30}$ The range of inventor and invention characteristics is quite large. Matching partnership observations to non-partnership observations with similar propensity scores we can behave as if there was random assignment to partnerships on inventor and invention characteristics, under the condition that there is ample partnership and non-partnership observations for each score. We examined this requirement and deleted 48 observations where there was no common support, leaving 724 observations for subsequent analysis. The region of common support for the score is [.02, .91], capturing the 1st to the 99th percentile. Because there is considerable overlap in the score distributions between partnership and non-partnership observations between the 1st to the 99th percentile the so-called balance property is satisfied and we can safely rely on the scores to provide reasonable matching.

Results of the inverse propensity-score weighted Tobit are provided in Model 5. As seen, the estimate of the partnership coefficient is again reduced, indicating that there is also selection on observable inventor and invention characteristics. The coefficient however does not decrease that much, it drops by an additional $6.3 \%$ and $9.7 \%$, in Tables 4 and 5 respectively. Therefore, after controlling for these selection effects, the partnership coefficient still remains large. The size of

\footnotetext{
${ }^{29}$ In another attempt to endogenize partnership formation we estimated an IV model with "the invention was stimulated at work" as exogenous predictor of partnership. It seems reasonable to presume that if the stimulus for the invention was at work it may make it easier for the inventor to find partners, but should not necessarily directly affect returns. The variable indeed was a significant predictor of partnership $(\mathrm{t}=2.94, \mathrm{p}<0.01)$ and the J-test confirmed that it was not correlated with the error term of the outcome regression (Chi- $2=0.09$ and 0.06 , $\mathrm{p}>0.10$.) Although the instrument is valid and reliable the results were not stable. This is a situation where the instrument simply is too weakly identified.

We also experimented with including all the inventor and invention characteristics in the production function. This produced results qualitatively similar to the ones reported in Tables 4 and 5 and were deemed to be of no major interest. Results available on request from the corresponding author.

${ }^{30}$ We included inventor gender, marital status, age, education, work experience, managerial experience, business experience, family business experience, years experience inventing, number of inventions developed, invention developed at work, invention stimulated at work, invention developed together with someone else, full-time, part-time, un- or self-employed when inventing. We also included the following invention characteristics: positive, pre-team R\&D expenditures, pre-team number of hours of effort, industry dummies, year dummies, and whether the fee paid to the CIC for the review was partly subsidized by a third party.
} 
Table 4: Tobit Regression Analysis of Commercialization Revenues

This Table presents latent variable results from Tobit regressions. The dependent variable is the natural logarithm of commercialization revenues. The independent variables are; partnership: a dummy variable $=1$ if an inventor formed a partnership to commercialize the innovation and 0 otherwise; partner with ability is a dummy $=1$ if the inventor formed a partnership and the partner contributed human and/or social capital and 0 otherwise; partner without ability but with financing is a dummy variable $=1$ if the inventor formed a partnership and the partner contribute financing but did not contribute neither human nor social capital; Positive, is a dummy variable $=1$ if the CIC assesment was positive, 0 otherwise; and $\mathrm{R}$ and $\mathrm{D}$ expenditures, and commercialization investment are the natural logarithms of $\mathrm{R}$ and $\mathrm{D}$ expenditures and commercialization investment, respectively. All data are in Cdn 2003 dollars. All regressions include dummy variables controlling for the project's industry, and the year the invention was assessed by the CIC. Standard errors in parenthesis. $* * *, * *$ or $*$ mean the coefficient is significant at the 1 percent, 5 percent or 10 percent level, respectively. Missing item data are multiple imputed using switching regression and assuming data are MAR. Coefficient estimates and standard errors are constructed using the formulae in Little and Rubin (1987).

\begin{tabular}{|c|c|c|c|c|c|c|}
\hline & Model 1 & Model 2 & Model 3 & Model 4 & Model 5 & Model 6 \\
\hline & Tobit & Tobit & Tobit & Tobit & $\begin{array}{c}\text { Propensity } \\
\text { Score } \\
\text { Weighted } \\
\text { Tobit } \\
\end{array}$ & Tobit \\
\hline \multicolumn{7}{|l|}{ Partnership effects } \\
\hline Partnership & $\begin{array}{c}15.25^{* * *} \\
(2.38)\end{array}$ & $\begin{array}{c}11.68^{* * *} \\
(2.14)\end{array}$ & $\begin{array}{c}7.54^{* * *} \\
(1.94)\end{array}$ & $\begin{array}{c}7.54^{* * *} \\
(1.92)\end{array}$ & $\begin{array}{c}7.06^{* * *} \\
(1.84)\end{array}$ & \\
\hline Partner with ability & & & & & & $\begin{array}{c}7.09^{* * *} \\
(2.01)\end{array}$ \\
\hline $\begin{array}{l}\text { Partner without ability } \\
\text { but with financing }\end{array}$ & & & & & & $\begin{array}{l}6.52^{*} \\
(3.69)\end{array}$ \\
\hline \multicolumn{7}{|l|}{ Control variables } \\
\hline Positive evaluation & & $\begin{array}{c}5.44^{\text {*** }} \\
(2.15)\end{array}$ & $\begin{array}{c}3.02 \\
(1.98)\end{array}$ & $\begin{array}{c}3.05 \\
(1.98)\end{array}$ & $\begin{array}{c}2.19 \\
(1.94)\end{array}$ & $\begin{array}{c}3.11 \\
(1.98)\end{array}$ \\
\hline R\&D expenditures & & $\begin{array}{c}1.57^{* * *} \\
(0.35)\end{array}$ & $\begin{array}{l}0.54^{*} \\
(0.33)\end{array}$ & $\begin{array}{c}0.48 \\
(0.33)\end{array}$ & $\begin{array}{l}-0.30 \\
(0.29)\end{array}$ & $\begin{array}{c}0.49 \\
(0.33)\end{array}$ \\
\hline $\begin{array}{l}\text { Commercialization } \\
\text { investment }\end{array}$ & & & $\begin{array}{c}1.61^{* * *} \\
(0.28)\end{array}$ & $\begin{array}{c}1.14^{* * * *} \\
(0.31)\end{array}$ & $\begin{array}{c}1.00^{* * *} \\
(0.31)\end{array}$ & $\begin{array}{c}1.19^{* * *} \\
(0.32)\end{array}$ \\
\hline $\begin{array}{l}\text { Commercialization } \\
\text { labor }\end{array}$ & & & & $\begin{array}{l}1.05^{* *} \\
(0.44)\end{array}$ & $\begin{array}{c}1.32^{* * *} \\
(0.48)\end{array}$ & $\begin{array}{l}1.01^{* *} \\
(0.44)\end{array}$ \\
\hline Constant & $\begin{array}{c}-25.07^{* * *} \\
(4.70)\end{array}$ & $\begin{array}{c}-34.22^{* * *} \\
(5.43)\end{array}$ & $\begin{array}{c}-31.78^{* * *} \\
(4.98)\end{array}$ & $\begin{array}{c}-32.71^{\text {*** }} \\
(5.05)\end{array}$ & $\begin{array}{c}-25.76^{* * *} \\
(4.49)\end{array}$ & $\begin{array}{c}-32.17^{* * *} \\
(4.98)\end{array}$ \\
\hline Sigma & $\begin{array}{c}14.88^{* * * *} \\
(1.44) \\
\end{array}$ & $\begin{array}{c}13.37^{* * * *} \\
(1.28) \\
\end{array}$ & $\begin{array}{c}11.97^{* * * *} \\
(1.13) \\
\end{array}$ & $\begin{array}{c}11.81^{* * * *} \\
(1.11) \\
\end{array}$ & $\begin{array}{c}9.51^{* * *} \\
(0.91) \\
\end{array}$ & $\begin{array}{c}11.87^{* * * *} \\
(1.12) \\
\end{array}$ \\
\hline Pseudo $R^{2}(\%)$ & 0.09 & 0.13 & 0.18 & 0.19 & 0.14 & 0.18 \\
\hline $\mathrm{N}$ & 772 & 772 & 772 & 772 & 724 & 772 \\
\hline
\end{tabular}


the effect is either $46 \%$ or $52 \%$ of the gross partnership coefficient in Model 1, respectively. The estimate from Table 4 implies that expected revenues of commercialized inventions increase by $29 \%$ going from solo-entrepreneurship to partnership, and that the probability of commercialization increases by 0.06 percentage points, which is a $97 \%$ percent increase over the commercialization rate of solo-entrepreneurs, both non-trivial impacts (at the sample means of other variables). The estimates of the impact of partnerships from Table 5 are somewhat stronger. Partnerships increase the probability of commercialization by 0.09 percentage points, and increase expected revenues by $49 \%$ (at the sample means of other variables).

Another result to note is that once we control for inventor and invention characteristics prior to collaboration, the coefficient for own financing becomes negative. This may be the case because our propensity score method uses observables that are correlated with the borrowing capacity of the inventor.

\subsection{Accounting for selection on unobservables}

Finally, we address the possibility that there is inventor-invention unobserved heterogeneity and measurement error of our identified selection effects. Here we utilize the fact that some partners only provide financial capital. We decompose the partnership effect as follows: Partnership =

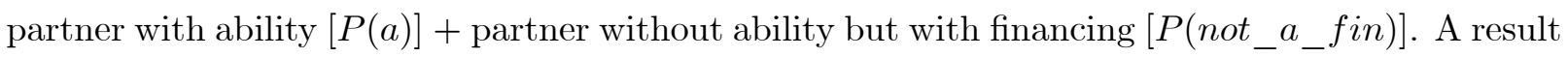
of our theoretical model is that the financial contribution of partners exclusively affect commercialization investments by relaxing liquidity constraints. An implication of this identifying restriction is that once we control for invention quality and commercialization investment, a partner that exclusively provides financing should not affect revenues in any other way, i.e., the coefficient for $P($ not_a_fin $)$ should be zero $(\gamma=0)$. If the estimated coefficient for $P\left(n_{\text {not_a_fin }}\right)$ is zero, $\widehat{\gamma}=0$, then the coefficient for $P(a)$ (label this $\widehat{\beta}$ ) should represent the partner's estimated value added. Alternatively, if $\widehat{\gamma}$ is positive, then there will likely be selection on unobservables and therefore $\widehat{\beta}$ may have an upward bias. ${ }^{31}$

Model 6 in Tables 4 (5) replaces Partnership with dummies for $P(a)$ and $P\left(n o t \_a \_f i n\right)$. In Table 4 we find that $\widehat{\beta}=7.09(p<0.01)$, and $\widehat{\gamma}=6.52(p=0.08)$. Results in Table 5 are similar. Therefore, it appears that $\widehat{\beta}$ is upwards biased due to selection on unobservables.

We proceed to separately identify the contribution of the partner's ability from selection on unobservables. Rather than imposing further parametric restrictions to obtain point identification,

\footnotetext{
${ }^{31}$ Our empirical strategy may over estimate the importance of selection on unobservables whenever the partner's financial investment generates additional value added beyond the partner's contributions of business contacts (social capital) and complementary technical skills (human capital). For instance, the partner's financial contribution may generate a positive signal about the quality of the venture.
} 
Table 5: Tobit Regression Analysis of Commercialization Revenues with Inventor's and Other's Capital

This table presents results from Tobit regressions. The dependent variable is the natural logarithm of commercialization revenues. The independent variables are partnership, a dummy variable $=1$ if an inventor formed a partnership to commercialize the innovation and 0 otherwise; partner with ability is a dummy variable $=1$ if the inventor formed a partnership and the partner contributed human and/or social capital and 0 othewise; partner ability but with financing is a dummy variable $=1$ if the inventor formed without a partnership and the partner contribute financing but did not contribute neither human nor social capital; Positive, which is a dummy variable $=1$ if the CIC assesment was positive, 0 otherwise; and own financing and other financing are the natural logarithms of the total $\mathrm{R}$ and $\mathrm{D}$ expenditures and the total commercialization investment from the inventor and the partner, respectively. All data are in Cdn 2003 dollars. All regressions include dummy variables controlling for the project's industry, and the year the invention was assessed by the CIC. Standard errors in parenthesis. ***, ** or * mean the coefficient is significant at the 1 percent, 5 percent, or 10 percent level, respectively. Missing item data are multiple imputed using switching regression and assuming data are MAR. Coefficient estimates and standard errors are cosntructed using the formulae in Little and Rubin (1987).

\begin{tabular}{|c|c|c|c|c|c|}
\hline & Model 2 & Model 3 & Model 4 & Model 5 & Model 6 \\
\hline & Tobit & Tobit & Tobit & $\begin{array}{c}\text { Propensity } \\
\text { Score } \\
\text { Weighted } \\
\text { Tobit } \\
\end{array}$ & Tobit \\
\hline \multicolumn{6}{|l|}{ Partnership effects } \\
\hline Partnership & $\begin{array}{c}10.28^{* * *} \\
(2.08)\end{array}$ & $\begin{array}{c}9.26^{* * *} \\
(2.08)\end{array}$ & $\begin{array}{c}8.83^{* * *} \\
(2.02)\end{array}$ & $\begin{array}{c}7.98^{* * *} \\
(1.92)\end{array}$ & \\
\hline Partner with ability & & & & & $\begin{array}{c}8.45^{* * * *} \\
(2.10)\end{array}$ \\
\hline $\begin{array}{l}\text { Partner without ability } \\
\text { but with financing }\end{array}$ & & & & & $\begin{array}{l}6.66^{*} \\
(3.81)\end{array}$ \\
\hline \multicolumn{6}{|l|}{ Control variables } \\
\hline Positive evaluation & $\begin{array}{c}5.03^{* * *} \\
(2.06)\end{array}$ & $\begin{array}{l}4.30^{* *} \\
(2.05)\end{array}$ & $\begin{array}{l}4.29^{* *} \\
(2.02)\end{array}$ & $\begin{array}{l}4.02^{* *} \\
(2.05)\end{array}$ & $\begin{array}{l}4.31^{* *} \\
(2.03)\end{array}$ \\
\hline Own financing & $\begin{array}{c}1.90^{* * *} \\
(0.36)\end{array}$ & $\begin{array}{c}1.74^{* * *} \\
(0.36)\end{array}$ & $\begin{array}{l}0.81^{* *} \\
(0.37)\end{array}$ & $\begin{array}{c}-0.56^{*} \\
(0.28)\end{array}$ & $\begin{array}{l}0.86^{* *} \\
(0.37)\end{array}$ \\
\hline External financing & & $\begin{array}{c}0.43^{* *} \\
(0.22)\end{array}$ & $\begin{array}{c}0.22 \\
(0.21)\end{array}$ & $\begin{array}{l}0.40^{*} \\
(0.22)\end{array}$ & $\begin{array}{c}0.25 \\
(0.22)\end{array}$ \\
\hline $\begin{array}{l}\text { Commercialization } \\
\text { labor }\end{array}$ & & & $\begin{array}{c}1.73^{* * *} \\
(0.44)\end{array}$ & $\begin{array}{c}2.13^{* * *} \\
(0.46)\end{array}$ & $\begin{array}{c}1.70^{* * *} \\
(0.44)\end{array}$ \\
\hline Constant & $\begin{array}{c}-36.38^{* * *} \\
(5.54)\end{array}$ & $\begin{array}{c}-35.37^{* * *} \\
(5.42)\end{array}$ & $\begin{array}{c}-33.67^{* * *} \\
(5.17)\end{array}$ & $\begin{array}{c}-24.01^{* * *} \\
(4.50)\end{array}$ & $\begin{array}{c}-33.22^{* * *} \\
(5.12)\end{array}$ \\
\hline Sigma & $\begin{array}{c}13.02^{* * * *} \\
(1.24)\end{array}$ & $\begin{array}{c}12.83^{* * *} \\
(1.22)\end{array}$ & $\begin{array}{l}12.31 \\
(1.17) \\
\end{array}$ & $\begin{array}{c}9.22^{* * *} \\
(0.88)\end{array}$ & $\begin{array}{c}12.39^{* * *} \\
(1.18)\end{array}$ \\
\hline Pseudo $R^{2}(\%)$ & 0.15 & 0.15 & 0.17 & 0.12 & 0.17 \\
\hline $\mathrm{N}$ & 772 & 772 & 772 & 742 & 772 \\
\hline
\end{tabular}


we construct a lower bound for $\widehat{\beta}$. The effect of selection on unobservables may differ between partners who provide abilities and partners who only provide financing. Indeed, Figure 1 shows that conditional on inventor's assets the partnerships that receive only financing $(A=1)$ have on average higher quality inventions than the rest of the partnerships. An implication of this result is that the higher the quality of an invention, the more likely it is that a partnership with only financing will be formed. This is equivalent to that $\operatorname{cov}(P(a), Q)<\operatorname{cov}(P($ not_a_fin $), Q)$. The sign of this inequality allows us to calculate a lower bound of the partner's ability: $\beta^{L}=$ $\widehat{\beta}-0.224 \widehat{\gamma} \cdot{ }^{32}$ Evaluating the right hand side of the bound at the estimated $\widehat{\beta}$ and $\widehat{\gamma}$, we obtain $\beta^{L}=5.63$ (std. err. 1.99, $p<0.00$ ) and $\beta^{L}=6.95$ (std. err. 2.06, $p<0.00$ ) for the estimations presented in Table 4 and Table 5 , respectively. Because we can safely assume that an upper bound for $\beta$ is $\widehat{\beta}$, the best estimate of partner's ability must lie in the range $\beta \in(5.63,8.45)$. The lower bound represents a partnership coefficient that is lowered from 7.54 in Model 4 to 5.63 in Model 6 of Table 4, a $25 \%$ reduction. The lower bound is $37 \%$ of the gross partnership coefficient in Model 1. The lower bound remains economically meaningful. For example, the mean probability of commercialization increases from 0.06 to 0.12 at the estimated lower bound value added, and the effect on expected revenues is a $38 \%$ increase. As the lower bound estimate is higher for results in Table 5 we refrain from reporting those details. Note that this method returns estimates quite similar to those from the method controlling for observed heterogeneity.

\section{Conclusion}

We investigated the value of informal capital for invention commercialization through business partnership formation. Partnerships are defined as when an inventor partners with someone to obtain human capital, social capital and/or financing to attempt commercializing an invention.

We develop a model of invention commercialization with partnership formation which reveals three selection effects. We show that partners are more likely to join inventor-inventions of high quality because these inventions allow them to obtain a higher return as compensation for their effort. A second insight is that among all potential partners the better partners are more likely to join inventors. Lastly, inventors with high quality inventions are more likely to be liquidity constrained and consequently more likely to seek partners for financing.

Raw data reveal that the effect of partnerships on project outcomes is considerable. The rate

\footnotetext{
${ }^{32}$ Define $\operatorname{bias}(\widehat{\beta})=\frac{\operatorname{cov}(P(a), Q)}{\operatorname{Var}(P(a))}$ and $\operatorname{bias}(\widehat{\gamma})=\frac{\operatorname{cov}(P(\text { not_a_fin }), Q)}{\operatorname{Var}\left(P\left(\text { not }_{-} a_{-} f i n\right)\right)} . \quad \operatorname{bias}(\widehat{\gamma})=\widehat{\gamma}$ since our theoretical model implies that the true value of $\gamma$ is 0 , while $\operatorname{bias}(\widehat{\beta})=\widehat{\beta}-\beta$. Rearranging and using that $\operatorname{Cov}(P(a), Q)<$ $\operatorname{Cov}(P($ not_a_fin $), Q)$, the lower bound $\beta^{L}$ for $\widehat{\beta}$, is $\beta^{L}=\widehat{\beta}-\left(\frac{\operatorname{Var}(P(\text { not_a_fin }))}{\operatorname{Var}(P(a))}\right) \widehat{\gamma}=\widehat{\beta}-0.224 \widehat{\gamma}$. We have replaced $\operatorname{Var}(P(a))$ and $\operatorname{Var}\left(P\left(a_{-}\right.\right.$not_a_fin $\left.)\right)$with their sample counterparts.
} 
of commercialization of inventions run by partnerships is five times larger than those run by solo entrepreneurs and revenues are almost ten times as large for partnerships as for solo entrepreneurs. The data reveal selection into partnerships based on invention quality: $33 \%$ of inventions rated as high quality were eventually joined by a partner, while only $17 \%$ of inventions with low quality were joined by a partner.

To examine selection on the demand for financing and the effect of external financing we note that the model implies that the probability to form a partnership to obtain financing increases with project quality, that the marginal investment return should drop once a partner provides financing (indicating liquidity constraints) and that the partnership coefficient should drop once controlling for the external investment. All predictions are supported in empirical analysis. Nevertheless, business partners do not appear to be the major source of external financing since the partnership effect was little reduced when introducing the external investment. Data also show that invention quality is lower when partners provide both ability and financing than when they only provide ability. This result suggests that the proportion of inventors with low assets may be large. It implies that selection on demand for financing may be less since the demand for financing may be primarily from inventors with lower quality inventions.

Accounting for selection, commercialization investment, external financing, and labor hours in Tobit analysis of commercialization revenues the remaining effect of partnership formation must be due to partners providing human and/or social capital or additional heterogeneity. We try to isolate the effect of partner ability from additional heterogeneity in two ways and find that it represents an increase in the probability of commercialization between 0.06 and 0.09 in both a propensity-score-weighted specification, and in an unobserved-heterogeneity specification. These are economically meaningful results as the probability of commercialization for a solo-entrepreneur is 0.06 . The estimated effect of partner ability on revenues is also large, representing approximately either a $29 \%$ or a $38 \%$ increase in expected revenues for commercialized inventions, depending on whether we use the propensity-score-weighted or the unobserved-heterogeneity specification. While conditioning on a range of observables as well unobservables, these estimates must still be interpreted as a treatment-on-the-treated effect, that is, the average effect of partners' human and social capital on project revenues for those partners selecting to join inventors. The reason is that partners' ability are heterogeneous and that partners with the highest ability are more likely to join inventors.

Our paper relates to the growing work in finance which tries to estimate the value added of venture capital to entrepreneurs. This effect has been hard to isolate because VCs select on project quality, they probably release credit constraints, and may also provide various forms of 
value added. The three effects appear simultaneously when projects are financed by VCs. In a recent paper Kerr, Lerner, and Schoar (2010) compare the impact of obtaining and not obtaining informal venture capital for entrepreneurs selecting to apply to two angel financing networks who are just above and below a funding cut-off, thereby eliminating much of explanations based on selection on unobservables. The authors estimate the joint effects of these networks releasing liquidity constraints and providing value added, conditional on entrepreneurs applying to these networks. We take a different approach than Kerr et al. (2010), in that we try to separately estimate both the selection and added value effects, and we also try to disentangle the effect of partners releasing liquidity constraints from the effects of their human and social capital.

Our setting is admittedly unique. We likely examine a domain where good business partners' human and social capital may be considerably more useful than in regular start-ups such as the mom-and-pop corner store. In this respect our sample is probably similar to that in Kerr's et al. (2010) study. At the same time our sample does not contain many projects that receive VC funding and so bargaining issues related to follow-on VC financing are probably unlikely. ${ }^{33}$ Nevertheless, our model and empirical methodology is with ease portable to other related domains of investigation and extendable to include analysis of bargaining. Our data further exhibited some limitations such as not linking the type of external investors with the amounts they provide, not counting the number of partners, not collecting contractual information (we doubt there exist much), and not providing information on the characteristics of potential partners. These limitations provide opportunities for future research.

The policy implications that one may draw from these estimations must be very tentative given the first-of-a-kind nature of this work. Nevertheless, if the results hold up in future work, it would suggest that for inventive projects, a major policy leverage to increase commercialization rates and revenues is to lubricate the market for finding skilled partners. Furthermore, the analysis echoes the sentiments by angel investors that they have a tough time finding sufficient investment opportunities (Mason, 2009). In this study the few projects with high initial quality had twice the participation rate by business partners than those with mediocre quality.

Finally, our work contributes to the literature on entrepreneurial choice. Lazear (2005) develop a theory of entrepreneurs as jacks-of-all-trades where he assumes that the entrepreneur must perform all tasks. The model we propose differs from Lazear's in that we allow individuals with insufficient skills to form partnerships to obtain the required skills rather than having to invest in own skill development. Our model also addresses project financing on which Lazear is silent.

\footnotetext{
${ }^{33}$ The fraction which received VC financing was $0.8 \%$, too small to be analyzeable in our study.
} 


\section{References}

Astebro, T., and I. Bernhardt (2003): "Start-Up Financing, Owner Characteristics and Survival," Journal of Economics and Business, 55(4), 303-320.

Astebro, T., S. Jeffrey, and G. Adomdza (2007): "Inventor Perseverance After Being Told to Quit: The Role of Cognitive Biases," Journal of Behavioral Decision Making, 20(3), $253-272$.

Astebro, T., And P. Thompson (2011): "Entrepreneurs: Jacks of all Trades or Hobos?," Research Policy, 40, 637-649.

Buuren, S van. Boshuizen, H. C., And K. D.L. (1999): "Multiple imputation of missing blood pressure covariates in survival analysis," Stat Med, 18, 681-694.

Bygrave, W. D., And P. D. Reynolds (2006): "Who Finances Startups in the USA? A Comprehensive Study of Informal Investors, 1999-2003," Babson College, Babson Kauffman Entrepreneurship Research Conference (BKERC).

Chemmanur, T., and Z. Chen (2006): "Venture Capitalists versus Angels: The Dynamics of Private Firm Financing Contracts," Working paper, Boston College.

Chemmanur, T., K. Krishnan, and D. Nandy (2009): "How does venture capital financing improve efficiency in private firms? A look beneath the surface," Unpublished working paper, Center for Economic Studies.

Cressy, R. (1996): "Are business startups debt rationed?," The Economic Journal, 106, 12531270.

Evans, D., And B. Jovanovic (1989): "An Estimated Model of Entrepreneurial Choice under Liquidity Constraints," Journal of Political Economy, 97(4), 808-827.

Fazzari, S. M., R. G. Hubbard, and B. C. Petersen (2000): "Investment-cash flow sensitivities are useful: A comment on Kaplan and Zingales," Quarterly Journal of Economics, $115(2), 695-705$.

Graham, J., And S. Hofer (2000): Multiple Imputation in Multivariate Research. Hillsdale, NJ: Erlbaum.

Grossman, S., And O. Hart (1986): "The costs and benefits of ownership: A theory of vertical and lateral integration," Journal of Political Economy., 94(4), 691-719.

Hall, B. H., And J. Lerner (2010): "The Financing of R\&D and Innovation," in Handbook of the Economics of Innovation, ed. by B. H. Hall, and N. Rosenberg, chap. 14. Elsevier 
North-Holland.

Harrison, R. T., C. M. Mason, and P. J. Robson (2010): "The Determinants of Long Distance Investing by Business Angels: Evidence from the United Kindom," Entrepreneurship and Regional Development, 22(2), 113-137.

HeCKman, J. (1979): "Sample selection bias as a specification error," Econometrica, 47, 153-161.

Hellmann, T., And M. Puri (2000): "The interaction between product market and financing strategy: the role of venture capital," Review of Financial Studies, 13, 959-84.

(2002): "Venture Capital and the Professionalization of Start-up Firms: Empirical Evidence," Journal of Finance, 57(1), 169-97.

Hirano, K., G. W. Imbens, and G. Ridder (2003): "Efficient Estimation of Average Treatment Effects Using the Estimated Propensity Score," Econometrica, 71(4), 1161-90.

Hochberg, Y. V., A. Luungqvist, and Y. Lu (2005): "Whom You Know Matters: Venture Capital Networks and Investment Performance," Journal of Finance, 62(1), 251-301.

Holmes, T., And J. A. Schmitz (1990): "A Theory of Entrepreneurship and Its Application to the Study of Business Transfers," Journal of Political Economy, 98(2), 265-94.

Holmstrom, B. (1982): "Moral hazard in partnerships," Bell Journal of Economics, 13, 324-40.

Hsu, D. (2004): "What Do Entrepreneurs Pay for Venture Capital Affiliation?," Journal of Finance, 59, 1805-44.

Kerr, W. R., J. Lerner, and A. Schoar (2010): "The Consequences of Entrepreneurial Finance: A Regression Discontinuity Analysis," Harvard Business School Unpublished Working Paper 10-086.

Kortum, S., And J. Lerner (2000): "Assessing the contribution of venture capital to innovation," The RAND Journal of Economics, 31, 674-692.

Kremer, M. (1993): "The O-ring theory of economic development," Quarterly Journal of Economics, 108(3), 551-75.

LAzEAR, E. P. (2005): "Entrepreneurship," Journal of Labour Economics, 23(4), 649-81.

Lazear, E. P., and K. L. Shaw (2007): "Personnel Economics: The Economist's View of Human Resources," Journal of Economic Perspectives, 21(4), 91-114.

Little, R. J. A., And D. Rubin (1987): Statistical analysis with missing data. John Wiley \& Sons, New York. 
Mason, C. M. (2009): "Public Policy Support for the informal Venture Capital Market in Europe," International Small Business Journal, 27(5), 536-56.

McDonald, J. F., And R. A. Moffitt (1980): "The Uses of Tobit Analysis," The Review of Economics and Statistics, 62 (2), 318-321.

Megginson, W., And K. A. Weiss (1991): "Venture capitalist certification in initial public offerings," Journal of Finance, 46(3), 879-903.

Mollica, M., And L. Zingales (2007): "The impact of venture capital on innovation and the creation of new business," Unpublished working paper, Univeristy of Chicago.

Puri, M., And R. Zarutskie (2008): "On the lifecycle dynamics of venture-capital- and nonventure-capital-financed firms," Unpublished working paper, Center for Economic Studies.

Repullo, R., And J. Suarez (2004): "Venture capital finance: A security design approach," Review of Finance, 8, 75-108.

Reynolds, P. D. (2005): Entrepreneurship in the United States: 2004 Assessment. Miami, FL, Florida International University.

Ruef, M., H. E. Aldrich, and N. M. Carter (2003): "The Structure of Founding partnerships: Homophily, Strong Ties, and Isolation among U.S. Entrepreneurs," American Sociological Review, 68(April), 195-222.

Sohl, J. (2010): "The Angel Investor Market in 2009: Holding Steady but Changes in Seed and Start-up Investments," Centure for Venture Research, http://www.unh.edu/news/docs/2009angelanalysis.pdf.

Sorensen, M. (2008): "How Smart is Smart Money? An Empirical Two-Sided Matching Model of Venture Capital," Journal of Finance, 52 (6), 2725-62.

Van-Osnabrugge, M., and R. Robinson (2000): Angel Investing: Matching Start-up Funds With Start-up Companies - A Guide For Entrepreneurs And Individual Investors. John Wiley \& Sons Inc.

Wiltbank, R. E. (2009): "Siding with the Angels: Business Angel Investing - promising outcomes and effective strategies," British Business Angel Association and NESTA.

Wiltbank, R. E., And W. Boeker (2007): "Returns to Angel Investors in Groups," Kauffman Foundation.

Wong, A., M. Bhatia, and Z. Freeman (2009): "Angel Finance: The other Venture Capital," Strategic Change, 18, 221-30. 
Woolridge, J. M. (2007): Econometric Analysis of Cross Section and Panel Data. MIT Press. 


\section{Appendix A: Inventor's maximization problem}

Let $V(Q, Z, A)$ define the value of an invention of quality $Q$ with a potential partner with ability $A$ evaluated at the profit maximizing capital investment as

$$
\begin{aligned}
V(Q, Z, A) & =\max \left\{V^{P}(Q, Z, A), V^{S}(Q, Z, A)\right\} \\
V^{P}(Q, Z, A) & =A(\beta)) Q K^{P *}+r\left(Z-K^{P *}\right)-\tau \\
V^{S}(Q, Z, A) & =Q K^{S^{*} \alpha}+r\left(Z-K^{S *}\right)
\end{aligned}
$$

where $\alpha \in(0,1), S$ and $P$ refer to solo-entrepreneurship and partnership, $K^{*}$ is the commercialization investment that maximizes the value of an invention. The capital investment that maximizes the inventor's profits from commercializing the invention on her own is

$$
K^{S *}=\left\{\begin{array}{lll}
\left(\frac{\alpha Q}{r}\right)^{1 /(1-\alpha)} & \text { if } & Q \leq \frac{r}{\alpha}(\lambda Z)^{1-\alpha} \\
\lambda Z & \text { if } & Q>\frac{r}{\alpha}(\lambda Z)^{1-\alpha}
\end{array}\right\}
$$

which may be constrained by the inventor's assets when the invention quality is sufficiently high $Q>\frac{r}{\alpha}(\lambda Z)^{1-\alpha}$. Note that $\frac{r}{\alpha}(\lambda Z)^{1-\alpha}$ is the level of quality such that the commercialization investment that maximizes profits is equal to the investment capacity of the inventor (i.e., $\left.\left(\frac{\alpha Q}{r}\right)^{1 /(1-\alpha)}=\lambda Z\right)$. The commercialization investment that maximizes the partnership's profits from commercializing the invention is

$$
K^{P *}=\left(\frac{\alpha A(\beta) Q}{r}\right)^{1 /(1-\alpha)}
$$

Evaluating the value of the venture at the commercialization investment that maximizes profits, we obtain that the difference between the value of partnership $\left(V^{P}\right)$ and the value of soloentrepreneurship $\left(V^{S}\right)$ is:

$$
V^{P}-V^{S}=\left\{\begin{array}{ll}
{\left[Q\left(\frac{\alpha Q}{r}\right)^{\alpha /(1-\alpha)}-r\left(\frac{\alpha Q}{r}\right)^{1 /(1-\alpha)}\right]\left[A^{1 /(1-\alpha)}-1\right]-\tau} & \text { if } \\
{\left[Q\left(\frac{\alpha Q}{r}\right)^{\alpha /(1-\alpha)}-r\left(\frac{\alpha Q}{r}\right)^{1 /(1-\alpha)}\right]\left[A^{1 /(1-\alpha)}-1\right]-\tau+} & \text { otherwise }(\lambda Z)^{(1-\alpha)} \\
{\left[Q\left(\frac{\alpha Q}{r}\right)^{\alpha /(1-\alpha)}-r\left(\frac{\alpha Q}{r}\right)^{1 /(1-\alpha)}-Q(\lambda Z)^{\alpha /(1-\alpha)}+r(\lambda Z)^{1 /(1-\alpha)}\right]} &
\end{array}\right\}
$$

An inventor and partner are indifferent between forming and not forming a partnership when $V^{P}-V^{S}=0$. The top equation equals the difference in profits for a non-capital-constrained project 
with and without a partner. The first bracketed term of that equation is necessarily positive and increasing with $Q$. The second bracket is also positive and its magnitude depends on the partner's ability.

The second equation shows the difference in profits between partnership and solo-entrepreneurship for those inventions where an inventor is liquidity constrained. As in the top equation, the first two bracketed terms together represents the value added of the partner's ability, which are increasing in $Q$. The bottom term is the difference between the profits of a liquidity constrained entrepreneur which received financing from a partner and the profits for the same entrepreneur had he not received external financing. This difference is the contribution of a business partnership exclusively formed to increase the capital investment level from the constrained investment level, $\lambda Z$, to the unconstrained level, $\frac{\alpha Q}{r}$. This term is therefore positive.

\section{Appendix B: Proofs.}

Proposition 1. There exist two cut-off rules, $\widehat{Q}^{P}(Z, A(\beta))$ and $\widehat{Q}^{C}(Z, A(\beta))$, that describes three potential choices that an inventor $(Z, Q)$ that meets a potential partner with ability $A(\beta)$ can make: no partnership; partnership with financing; and partnership with no financing.

Proof. We start by showing that there exist a level of $Q$ such that for a fixed $Z$ an inventor is liquidity constrained. Consider two cases: the inventor meets a partner, or she does not. If the inventor does not meet a partner, the constrained investment level is $K^{*}=\lambda Z$ for $Q>$ $\frac{r}{\alpha}(\lambda Z)^{1-\alpha}=\widehat{Q}^{C}(Z, p)$. Note that $\widehat{Q}^{C}(Z, p)$ is quality level such that the solo-entrepreneur capital investments that maximizes profits are equal to the inventor's maximum investment capacity $\lambda Z$. If the inventor meets a partner, we have $K^{*}=\lambda Z$ for $Q>\frac{r}{\alpha A(\beta)}(\lambda Z)^{1-\alpha}=\widehat{Q}^{C}(Z, A(\beta))$, where $A(\beta)$ is the partner's ability.

The second cutoff rule $\widehat{Q}^{P}(Z, A(\beta))$ is the level of invention quality that makes an inventor indifferent between forming a partnership and commercializing the invention solo. Let $V(Q, Z, A)=$ $\max \left\{V^{P}(Q, Z, A), V^{S}(Q, Z, A)\right\}$ be the value of an invention. $\widehat{Q}^{P}(Z, A(\beta))$ is the invention quality such that $V^{P}\left(\widehat{Q}^{P}, Z, A(\beta)\right)=V^{S}\left(\widehat{Q}^{P}, Z, A(\beta)\right)$. There exists a unique cutoff $\widehat{Q}^{P}(Z, A(\beta))$. For that to follow, it must be the case that $\widetilde{V}(Q)=V^{P}(Q, Z, p)-V^{S}(Q, Z, p)$ is strictly increasing with $Q$ and that the value of $\widetilde{V}(Q)$ is positive for some $Q$ (e.g., a $Q$ sufficiently high) and negative for another $Q$ (e.g., $Q=0$ ). We will then focus our analysis on showing that $\widetilde{V}(Q)$ is increasing in $Q$. Let us first consider a $\mathrm{Q}$ such that the inventor is liquidity constrained, i.e., $K=\lambda Z$. Then, as $Q$ increases, the value of $V^{P}$ increases at a faster pace than $V^{S}$. Next consider the inventor not liquidity constrained. Here $V^{P}$ increases at a faster pace than $V^{S}$ with $Q$ because a marginal change in $Q$ in a partnership is amplified through the partner's ability $A(\beta)$. This is because $A(\beta)$ 
and $Q$ enters multiplicatively in the revenue of an innovation. Therefore, we can conclude that, for a fixed $Z$ and $A(\beta)$, there exist an invention quality level $\widehat{Q}^{P}(Z, A(\beta))$ that makes an inventor indifferent between forming a partnership or working solo.

Proposition 2. For a fixed wealth $Z$, the cutoff rule $\widehat{Q}^{P}(Z, A(\beta))$ is decreasing with the partner's ability $A(\beta)$. Therefore, the probability of forming a partnership increases with the quality of the invention $Q$.

Proof: We would like to show that the liquidity cutoff $\widehat{Q}^{C}(Z, A(\beta))$ and the partnership cutoff $\widehat{Q}^{P}(Z, A(\beta))$ are decreasing functions with the partner's ability $A(\beta)$. That $\widehat{Q}^{C}(Z, A(\beta))$ is decreasing with $A(\beta)$ for a fixed $\mathrm{Z}$ is straightforward because $\widehat{Q}^{C}(Z, A(\beta))=\frac{r}{\alpha A(\beta)}(\lambda Z)^{1-\alpha}$. Showing that $\widehat{Q}^{P}(Z, A(\beta))$ decreases with $A(\beta)$ is somewhat more involved. For a fixed $Q$, the higher $A(\beta)$ is, the higher is the the capital investment, and so is the value of partnership $V^{P}$. The value of solo-entrepreneurship $V^{S}$ does not change with $A(\beta)$, so the difference between partnership and entrepreneurship increases with $A(\beta)$. Now we have to show that the higher $Q$ is, the lower is the different between $V^{P}$ and $V^{S}$. For a fixed $A(\beta)$, the lower $Q$ is, the lower is the capital investment and so is the value of partnership and the value of solo-entrepreneurship. However, because $A(\beta)$ and $Q$ enter multiplicatively in the revenue function, the value of partnership will drop more than the value of solo-entrepreneurship. Therefore, we conclude that the higher is the partner's ability $A(\beta)$, the lower is the cutoff $\widehat{Q}^{P}(Z, A(\beta))$.

Proposition 3. Inventors who are liquidity constrained are more likely than unconstrained inventors to form partnerships.

Proof: To prove this result we must show that for a fixed inventor's wealth $Z$, the probability to form a partnership is higher for an invention with quality $Q>\widehat{Q}^{C}(Z, A(\beta))$ than for the rest of the inventions $Q \leq \widehat{Q}^{C}(Z, A(\beta))$. The probability to form a partnership is the probability to meet a partner with ability $A(\beta)$ such that $Q>\widehat{Q}^{P}(Z, A(\beta))$. Let us start with inventions where an inventor is not liquidity constrained, i.e., the quality level is such that $Q \leq \widehat{Q}^{C}(Z, A(\beta))$. Here the benefit of partnership is exclusively given by the partner's ability $A(\beta)$ and partnerships will only be formed for inventions with invention quality above $\widehat{Q}^{P}(Z, p)$ (see proposition 2). This implies that when $Q \leq \widehat{Q}^{C}(Z, A(\beta))$ the probability of partnership will tend to be low. Alternatively, if an inventor is liquidity constrained (i.e., $Q>\widehat{Q}^{C}(Z, A(\beta))$ ), the benefit to form a partnership is due to both the partner's ability $A(\beta)$ as well as the increase in the level of capital investment from the constrained level $\lambda Z$ to the unconstrained $K^{*}=\left(\frac{\alpha A(\beta) Q}{r}\right)^{1 /(1-\alpha)}$. The two effects together are associated with a lower cutoff to form a partnership $\widehat{Q}^{P}(Z, A(\beta))$ than for inventions held by inventors that were not liquidity constrained, i.e., $Q \leq \widehat{Q}^{C}(Z, A(\beta))$. Therefore, the probability 
to form a partnership is higher when the inventor is liquidity constrained than for the rest of inventions.

Proposition 4. Conditional on a partnership being formed, the average ability of a partner is strictly higher than the ability of the average potential partner.

Proof: Recall that $A(\beta)$ is the realization of a stochastic random variable that determines the partner's ability. Before meeting a partner, the ability of a potential partner is $E[A(\beta)]$. For a fixed invention quality $Q$ and inventor's wealth $Z$, the probability of partnership is the probability a partner $A(\beta)$ meets a inventor with $Q>\widehat{Q}^{P}(Z, A(\beta))$. Since the function $\widehat{Q}^{P}(Z, A(\beta))$ is strictly monotone with $A(\beta)$, for a fixed invention quality $Q$, we can define the probability of partnership $\operatorname{Pr}\left(A(\beta)>\widehat{Q}^{P[-1]}(Z, Q)\right)$, where $\widehat{Q}^{P[-1]}$ is the inverse function of $\widehat{Q}^{P}$. We want to show that conditional on a partnership being formed, the ability of the average partner is higher than the expected ability of a partner, i.e., $\left.E\left[A(\beta) \mid A(\beta) \geq \widehat{Q}^{P[-1]}(Z, Q)\right]\right]>E[A(\beta)]$. This inequality holds for all $Q$ in a partnership because $A(\beta) \geq 1$. Therefore, the ability of the average partner that formed a partnership is higher than the average potential partner.

Proposition 5. For a fixed ability $A$, (a) the cutoff rule $\widehat{Q}^{C}(Z, A)$ is increasing with the inventor's assets $Z$; and (b) the cutoff rule $\widehat{Q}^{P}(Z, A)$ is increasing with the inventor's assets $Z$ up to a level of inventor's assets where $\widehat{Q}^{P}(Z, A)$ is independent of $Z$.

Proof: First, we show that cutoff rule $\widehat{Q}^{C}(Z, A)$ is increasing with the inventor's assets $Z$. Let us consider a level of invention quality $Q$ such that for a fixed $Z$ an inventor is liquidity constrained. There are two cases to analyze. (1) If the inventor does not meet a partner, the constrained investment level is $K^{*}=\lambda Z$ for $Q>\frac{r}{\alpha}(\lambda Z)^{1-\alpha}=\widehat{Q}^{C}(Z, A)$. It is easy to see that the function $\widehat{Q}^{C}(Z, A)$ is increasing in $Z$ because $\alpha \in(0,1)$. (2) If the inventor meets a partner, we have $K^{*}=\lambda Z$ for $Q>\frac{r}{\alpha A}(\lambda Z)^{1-\alpha}=\widehat{Q}^{C}(Z, A)$. Again, it is easy to see that the function $\widehat{Q}^{C}(Z, A)$ is increasing in $Z$ because $\alpha \in(0,1)$. Second, we show that $\widehat{Q}^{P}(Z, A)$ is increasing with the inventor's assets $Z$ up to a level of inventor's assets where $\widehat{Q}^{P}(Z, A)$ is independent of $Z$. Let us consider a sufficiently high level of invention quality $Q$ and partner ability $A$ such that a partnership can be profitable. Note that for a given $Q$ and $A$, there exits a level of inventor's assets $\bar{Z}(Q, A)$ above which the inventor is not liquidity constrained. Above this level of inventor assets, the cutoff rule $\widehat{Q}^{P}(Z, A)$ will be independent of $Z$ because the partner does not provide value added through the channel of relaxing liquidity constraints. Below the level of assets $\bar{Z}(Q, A)$, the inventor is liquidity constrained and thus the partner provides additional value added through relaxing the liquidity constraint. Note that the higher the assets of the inventor, the lower the potential benefits of partnership and thus the higher is the cutoff $\widehat{Q}^{P}(Z, A)$. 